\title{
Maritime-Continental Contrasts in the Properties of Low-Level Clouds: A Case Study of the Summer of the 2003 Yamase, Japan, Cloud Event
}

\author{
Nawo Eguchi, ${ }^{1}$ Tadahiro Hayasaka, ${ }^{2}$ and Masahiro Sawada ${ }^{3}$ \\ ${ }^{1}$ Research Institute for Applied Mechanics, Kyushu University, 6-1 Kasuga Park, Kasuga, Fukuoka 816-8580, Japan \\ ${ }^{2}$ Center for Atmospheric and Oceanic Studies, Graduate School of Science, Tohoku University, 6-3 Aoba, \\ Aramaki-aza, Aoba-ku, Miyagi, Sendai 980-8578, Japan \\ ${ }^{3}$ Atmosphere and Ocean Research Institute, The University of Tokyo, 5-1-5 Kashiwanoha, Chiba, Kashiwa-shi 277-8564, Japan
}

Correspondence should be addressed to Nawo Eguchi; nawo@riam.kyushu-u.ac.jp

Received 7 October 2013; Accepted 22 January 2014; Published 13 March 2014

Academic Editor: Ismail Gultepe

Copyright (C) 2014 Nawo Eguchi et al. This is an open access article distributed under the Creative Commons Attribution License, which permits unrestricted use, distribution, and reproduction in any medium, provided the original work is properly cited.

\begin{abstract}
Satellite data were used to investigate maritime-continental differences in the characteristics of the low-level cloud (the Yamase cloud) that covered northeast Japan during the summer of 2003. The features of the Yamase cloud were found to be almost the same as those of general stratus clouds but with a smaller effective radius $\left(r_{e}\right)$ and a greater optical thickness $(\tau)$ over land, as compared with general stratus clouds. The values of $r_{e}$ over land (average, $\left.11.8 \mu \mathrm{m}\right)$ were smaller than those over the ocean $(13.5 \mu \mathrm{m})$, and the values of $\tau$ and the cloud water path over land $\left(20\right.$ and $145 \mathrm{gm}^{-2}$, resp.) showed larger spatial variances than those over the ocean (10 and $86 \mathrm{gm}^{-2}$, resp.), although the cloud top altitude was nearly the same over both ocean and land (1-3 km). We suggest that this maritime-continental contrast is a result of the combined effects of topography and aerosols characteristics. The Yamase wind blowing from the ocean is forced upwards in coastal regions by the steep mountainous terrain. The updraft drives the inhomogeneity in cloud parameters, and a convective-like cloud develops without precipitation. The relationship between $r_{e}$ and $\tau$ suggests high aerosol concentrations and unstable conditions over land.
\end{abstract}

\section{Introduction}

Yamase is a localized meteorological phenomenon that develops during the summer (May-August) on the Pacific Ocean side of the Tohoku area of Japan (northeast of Honshu Island), in an area commonly known as Sanriku (the approximate location is indicated by the black box in Figure 3(a)). The Yamase is generally characterized by a cold and moist northeasterly wind associated with the Okhotsk High (e.g., [1]), which leads to the formation of a stratiform low-level cloud over the ocean that extends inland at Sanriku; the lowlevel cloud over ocean and adjacent land areas is known as the Yamase cloud. Under these conditions, the Sanriku area experiences unseasonably cool weather, as the Yamase cloud reduces incoming solar radiation and lowers surface temperatures.
More generally, the Yamase cloud is part of the marine stratiform cloud (MSC) that governs weather conditions in the North Pacific during the boreal summer; moreover, the northwestern Pacific region (including the Yamase area) is the region of the largest interannual variability in MSC occurrence frequency (another region with even greater interannual variability in the MSC is the subtropical west coast of North America) [2]. Discussion continues regarding the relationships between MSC frequency, sea surface temperatures (SSTs), and the background meteorological field, as do investigations into MSC properties and the radiative impacts of the MSC. A better understanding of the Yamase cloud may therefore improve our understanding of the characteristics and formation processes of the MSC.

The parameters that contribute to the formation of stratus cloud (low-level liquid cloud) over the ocean are 
heat flux (sensible and latent) at the sea surface, cloud radiative cooling/heating in the top and bottom layers, SSTs, and aerosol characteristics. These parameters are closely correlated. However, the processes of stratus formation over the ocean are not fully understood as the heat and moisture balances are complex and difficult to observe simultaneously. In addition, the SST distribution in the northwestern Pacific (including offshore near Sanriku) is complicated by mixing of the Oyashio (cold) and Kuroshio (warm) currents. Consequently, the formation processes of the Yamase cloud over the ocean are complex and are not simply driven by temperature differences between cold winds and warm SSTs. In addition to in situ stratus formation offshore at Sanriku, we consider stratus clouds developed in the North Pacific and blown to the Sanriku area.

Previous studies of the Yamase cloud have focused mainly on cloud formation processes over the ocean and on localized characteristics of the Yamase cloud derived from groundbased observations. Shipboard and airborne observations of the Yamase cloud obtained during the summer of 2006 show that the effective radius and cloud water content of the Yamase cloud over the ocean are nearly the same as those of low-level clouds forming in other areas of the globe [3]. Several studies have investigated the Yamase cloud using satellite data (e.g., [4]), but they have mainly focused on the properties of the cloud over the ocean and over limited time periods. Kojima et al. [4], based on cloud data from channels $1(0.63 \mu \mathrm{m})$ and $3 \mathrm{~A}(1.6 \mu \mathrm{m})$ of the NOAA (National Oceanic and Atmospheric Administration's Advanced Very High Resolution Radiometer (AVHRR)), showed that the stratiform low-level cloud over the ocean that occurred during June 2325,2003 , was thin and that the cloud parameters (such as optical depth and effective radius) are similar to those of lowlevel clouds from other regions (as reported by [5]).

The Yamase cloud generally forms over the ocean and extends inland due to an easterly or northeasterly wind, indicating that the Yamase clouds present over ocean and land form under the same synoptic weather conditions. The different characteristics of low-level clouds over the land and ocean are known (e.g., [6]); that is, the $r_{e}$ of liquid cloud over land is less than that over the ocean, and the $\tau$ over land is larger than that over the ocean on account of different amounts and types of cloud condensation nuclei (CCN) (e.g., [6, 7]). However, these characteristic differences also depend on location and season [8], and more rigorous statistical results might be obtained by accounting for localized weather conditions at the time of observation. A better knowledge of the properties of the Yamase cloud and the maritime-continental contrast can contribute to our general understanding of the behavior and formation processes of stratiform clouds. While the formation processes of the Yamase cloud over the ocean are clearly important, this study uses satellite data to investigate mesoscale temporal and spatial properties of stratus (low-level liquid cloud) formation over land and ocean during Yamase phenomena and considers the differences in properties of clouds (e.g., cloud top height, $r_{e}$, and $\tau$ ) over land and ocean.

The remainder of the paper is organized as follows. The next section presents data analysis procedures (Section 2);
Section 3 describes three Yamase cloud events, including the stratus cloud that developed in an immediate pre-Yamase period, and a brief summary of Yamase cloud properties. A discussion of differences in the characteristics of Yamase clouds over land and ocean is presented in Section 4, and, finally, Section 5 presents concluding remarks.

\section{Data}

The present study focuses on the properties of stratiform low-level clouds that develop over both land and ocean during Yamase events. Four cloud properties, namely, cloud top pressure, effective radius $\left(r_{e}\right)$, optical thickness $(\tau)$, and cloud water path, were derived from the Moderate Resolution Imaging Spectroradiometer (MODIS is carried onboard the NASA's (National Aeronautics and Space Administration) Aqua and Terra satellites) Level 2 Cloud Products (MOD06 and MYD06) $[9,10]$. The horizontal resolution of the cloud top pressure data was $1 \mathrm{~km}$, while that for the three other properties was $500 \mathrm{~m}$.

The cloud top pressure was retrieved using the $\mathrm{CO}_{2}$ slicing method with four bands (from 13 to $15 \mu \mathrm{m}$ ). The height of the radiative center of the cloud is near the top of optically thick clouds and is near the middle of optically thin clouds [10]. A comparison of the heights of cloud tops from MODIS (Collection 5) and Cloud-Aerosol Lidar with Orthogonal Polarization (CALIOP) data shows height differences within a few hundred meters for the lower clouds (and less than $5 \mathrm{~km}$ for top heights of the clouds) in northern middle latitudes [11]. The CALIOP lidar sensor is onboard the Cloud-Aerosol Lidar and Infrared Pathfinder Satellite Observations (CALIPSO) satellite, and both CALIPSO and Aqua satellite are members of the A-Train, which constructs some satellites along same orbit within 30 minutes, and thus the differences between the observation times of the two satellites are within one minute. Previous studies have pointed out that cloud top heights derived from MODIS spectra tend to be about $2 \mathrm{~km}$ higher than those obtained by ground-based observations, at least in some cases $[12,13]$. However, as will be described in Section 3, the vertical profiles of temperature and relative humidity obtained by radiosonde at Misawa $\left(141.38^{\circ} \mathrm{E} 40.7^{\circ} \mathrm{N}\right)$ show that the cloud top heights obtained by MODIS and sonde are in good agreement.

The values of $\tau$ and $r_{e}$ were retrieved using, respectively, the $0.645 \mu \mathrm{m}$ and $2.13 \mu \mathrm{m}$ bands over land and the $0.858 \mu \mathrm{m}$ and $2.13 \mu \mathrm{m}$ bands over ocean; however, the influence of the different bands used for data retrieval over land and ocean is small (pers. comm. T. Y. Nakajima). Values of $r_{e}$ derived from the $2.13 \mu \mathrm{m}$ MODIS channel were mainly located in the upper part of the middle layer of the cloud; the uncertainty of $r_{e}$ is approximately 1-3 $\mu \mathrm{m}$ [9]. The uncertainty associated with the cloud liquid water path is, on average, $19 \mathrm{~g} \mathrm{~m}^{-2}$ [14].

The analysis period during July-August 2003 was selected because this period experienced the coolest weather conditions associated with a Yamase event since the Terra and Aqua satellites' onboard MODIS data acquisition began in 1999 and 2002, respectively. During the summer of 2003, development of the Okhotsk High was more extensive than that during 
a normal summer. In particular, the Okhotsk High maintained its strength for many days, both at the end of July and in the middle of August [15]; consequently, the Yamase clouds were well developed during the period investigated in this study.

The Terra and Aqua satellites' onboard MODIS observed the atmosphere over the Yamase area on average twice each day during the analysis period, at 10:30 (22:30) and 13:30 (01:30) local time. However, the cloud properties (other than cloud top pressure) can be retrieved during the day because the retrieval process uses shortwave infrared band data.

In this study, the Yamase area was defined as the region of $139^{\circ} \mathrm{E}-143^{\circ} \mathrm{E}$ and $37.5^{\circ} \mathrm{N}-41.5^{\circ} \mathrm{N}$. The area covers the eastern side of the Tohoku district, where the Ou Mountain chain is oriented in a N-S direction. The Ou Mountains reach elevations of 1000-2000 m, with a maximum elevation of $2038 \mathrm{~m}$ at Iwate Mountain $\left(141^{\circ} \mathrm{E}, 39.5^{\circ} \mathrm{N}\right)$. The Kitakami Mountains are located between the Ou Mountains and the east coast of Tohoku, the latter being dominated by rias. The location of these mountains (Kitakami Mountains and Ou Mountains) was identified using topographic data from the digital elevation model (DEM) of the Japan Meteorological Agency (JMA) mesoscale numerical model (horizontal resolution, approximately $5 \mathrm{~km}$ ). Note that the elevations of the topographic contours in the figures in the Results (Section 3) are underestimates of actual elevations, as the DEM data were smoothed to provide the $5 \mathrm{~km}$ resolution.

We used meteorological parameters (temperature, relative humidity, zonal and meridional wind fields, and vertical winds) from the prediction and analysis data of the JMA mesoscale model [16]. The JMA mesoscale analysis data, which was used to define the initial conditions of the operational mesoscale model (MSM), is based on a $0.25^{\circ} \times$ $0.2^{\circ}$ grid and a 3-hourly time interval. Meteorological data for the times nearest to the MODIS observation times were used for comparisons of JMA mesoscale and MODIS data.

Rain data used in this study were obtained from the analysis of precipitation data produced by JMA, which is derived from ground-based measurements, such as weather radar and rain gauges [17]. Analysis of the precipitation data was performed at grid intervals of $2.5 \mathrm{~km}$ every 30 minutes. In addition, rain gauge data were also obtained from the Automated Meteorological Data Acquisition System (AMeDAS) operated by JMA at 65 locations across the Sanriku area.

\section{Results}

3.1. Meteorological Field. On the Pacific side of Japan, especially in the Sanriku area, the summer of 2003 was the coldest summer of the last decade. The summer monthly average surface temperature was approximately $3^{\circ} \mathrm{C}$ lower, and sunshine was reduced by $20 \%$ to $40 \%$, as compared with the 30-year record of monthly averages. In contrast, precipitation at Sanriku was 1.2-3 times higher during the summer of 2003 than during an average summer $[18,19]$.

The cold conditions during the summer of 2003 were caused by the high frequency of cloud cover generated by northeasterly winds associated with an enhanced Okhotsk High [20] and a weak Pacific High. The Okhotsk anticyclone, centered on the Sea of Okhotsk, was stronger and more persistent in 2003 than during an average summer, while the Pacific High was weaker than average. Values of the Okhotsk High index, defined by sea surface pressures anomalies relative to climatological averages in the area between $140^{\circ}-150^{\circ} \mathrm{E}$ and $45^{\circ}-55^{\circ} \mathrm{N}$, show two periods of July 20-24, 2003, and August 12-18, 2003, when the Okhotsk High was particularly enhanced.

Reference [21] reported that the Okhotsk High in July 2003 displayed some contrasting characteristics as compared with August of the same year. They found that, at the end of July, the vertical structure of the anticyclone over the Sea of Okhotsk was barotropic from the surface to the upper troposphere. A blocking high over East Siberia, associated with a stationary Rossby wave, modulated the Okhotsk High, which is the standard situation for the Okhotsk High in summer. Figures 1(a) and 1(c) show that easterly and northerly winds were enhanced at $500 \mathrm{hPa}$ and $975 \mathrm{hPa}$ at the end of July and that this enhancement was caused by the Okhotsk High and the blocking high, respectively. The easterly and northerly winds advect wet and dry air, respectively, to the northeastern area of Japan in the lower and middle troposphere, respectively.

In contrast, during mid-August, the vertical structure of the Okhotsk High was baroclinic. The Okhotsk High developed during this period due to the low SSTs and the advection of cold air in the lowermost troposphere but survived for only a brief period [21]. Figures 1(b) and 1(d) show that, in the middle of August, the northeasterly and southwesterly winds were strong at $975 \mathrm{hPa}$ and $500 \mathrm{hPa}$, respectively. The anticyclonic wind associated with the Pacific High at $975 \mathrm{hPa}$ is also evident. At $975 \mathrm{hPa}$, the relative humidity $(\mathrm{RH})$ during both periods was high over the Pacific Ocean and was also high at the coastline, especially in the Tohoku area, during the early period, and along the Kuroshio Current and its extension in the later period. In the later period (Figure 1(b)), the high $\mathrm{RH}$ at $500 \mathrm{hPa}$ was caused by the front located to the south of the main island of Japan. As a result, the high-level cloud cover frequently extended over the northern part of Japan at this time.

In contrast to the summer of 2003, the summer of 2004 was extremely hot, the Okhotsk High was less active, and the Pacific High was active and close to Japan. Low-level clouds were seldom observed over the Pacific side of Japan during the summer of 2004. The contrast in meteorological patterns between 2003 and 2004 suggests that Yamase cloud formation is closely related to changes in the synoptic-scale wind field over eastern Asia.

3.2. Occurrence Frequency of the Yamase Cloud. On average, the Terra and Aqua satellites' onboard MODIS collected data over northern Japan twice each day. We analyzed the MODIS data when 1000 or more pixels of data (with the exception of missing pixel data at the $500 \mathrm{~m}$ resolution level) were available in the Sanriku area. Data from the edge of the MODIS swath were not used in the analysis because of 


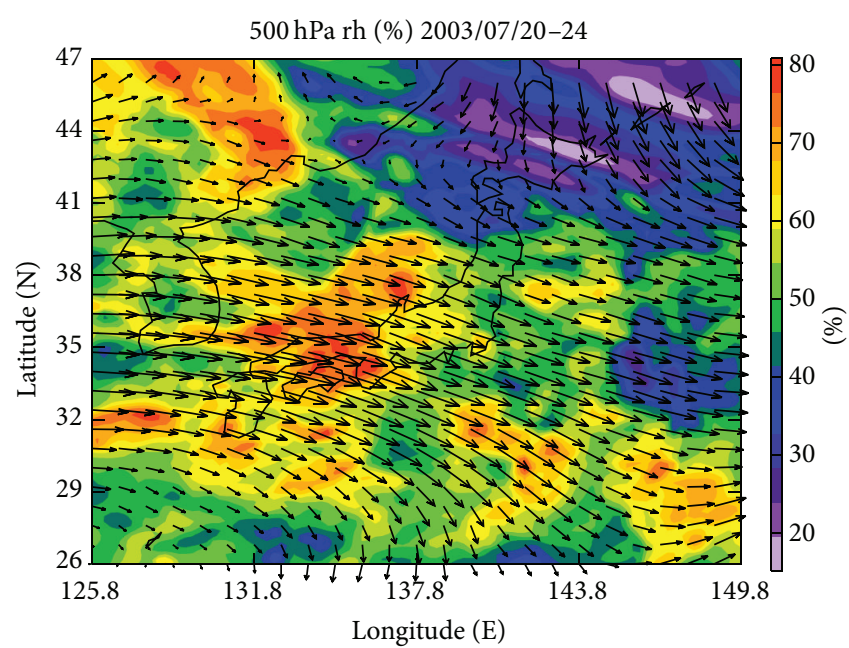

(a)

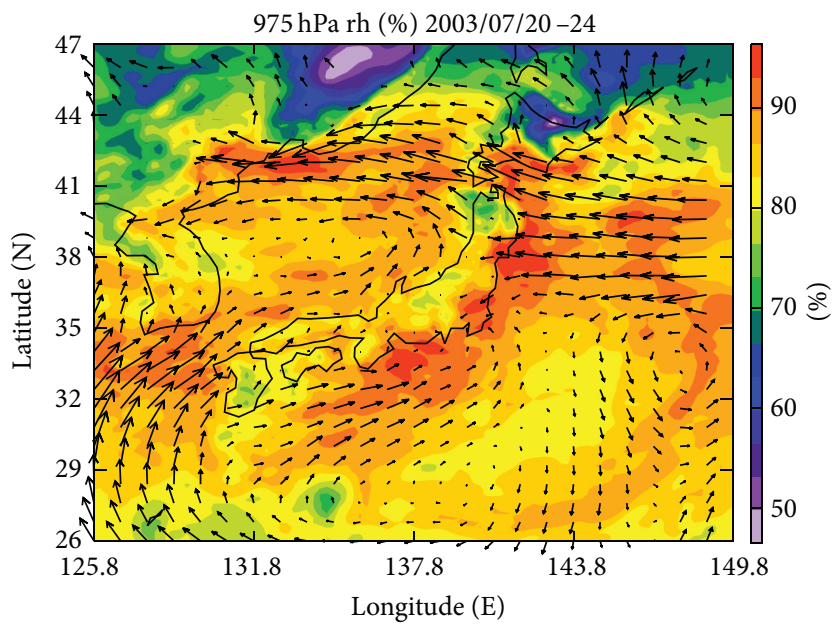

(c)

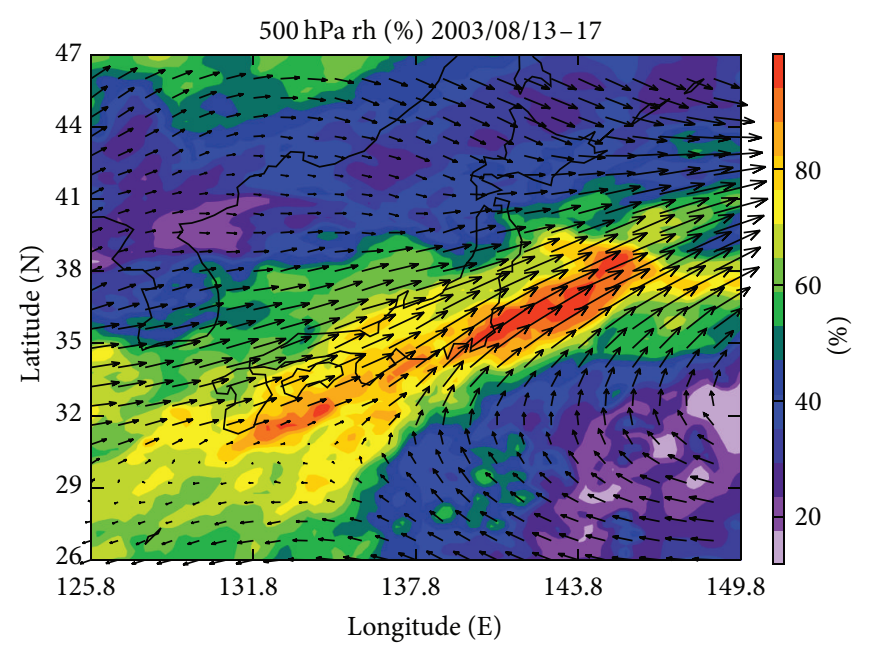

(b)

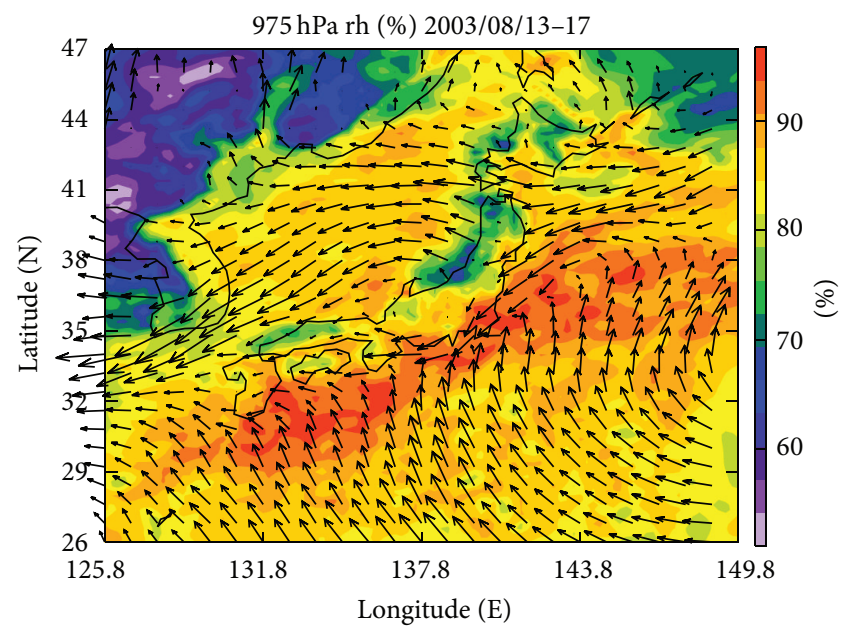

(d)

FiguRE 1: Distribution of average relative humidity [\%] (color shading) and the horizontal wind field (vectors) for July 20-24 (a and c) and August 13-17 (b and d) at $500 \mathrm{hPa}(\mathrm{a}$ and b) and $975 \mathrm{hPa}(\mathrm{c}$ and d).

sparse data coverage in these regions. In the present study, the upper and lower clouds were defined as clouds with cloud top pressures above and below $600 \mathrm{hPa}$ (approximately $4 \mathrm{~km}$ altitude), respectively. This scheme was chosen because the histogram of cloud top pressures during the analysis period was clearly divided at the $600 \mathrm{hPa}$ pressure level into lower and upper clouds top pressure. The modes (maximum frequencies) of cloud top pressures during the analysis period were located near $800 \mathrm{hPa}$ and $350 \mathrm{hPa}$. The MODIS is a passive sensor that observes visible and shortwave infrared channels for the retrieval of cloud parameters; therefore, it tends to preferentially detect upper clouds rather than lower clouds, and lower clouds may be obscured under multilayer cloud conditions.

During the two analysis periods (Table 1; July 18-28 and August 12-19, 2003), the occurrence frequency of clouds over the study area in the 38 scenes was approximately $95 \%$, and the occurrence frequencies of only upperlevel and only lower-level clouds were 55.3\% (21 scenes) and $18.4 \%$ (7 scenes), respectively. The frequency of mixed scenes with both upper and lower clouds was $21.0 \%$ (8 scenes). A comparison of the two analysis periods shows that the upper cloud frequency was nearly the same in both periods (76\%), but the lower cloud frequency was $47.6 \%$ in July and only $29.4 \%$ in August.

The occurrence frequency of lower (upper) cloud was $39 \%$ (76\%) with 15 (29) cases. The present analysis considers 12 out of the 15 cases of lower cloud but only a small proportion of upper cloud cases. The occurrence frequencies of lower and upper clouds reported here are similar to those obtained by [22], who found an occurrence frequency of cloudy sky during the Yamase period of approximately $90 \%$, as deduced from ground-based observations. The total frequencies of upper and middle clouds were both $70 \%$ and the lower cloud frequency was $30 \%$.

The high cloud during the analysis period was caused mainly by fronts and low-pressure systems (synoptic scale phenomena). The influence of topography (e.g., mountains 
TABLE 1: Classification of a MODIS scene over Sanriku into upper-level cloud, lower-level cloud, mixed (upper and lower) cloud, and clear sky conditions. The lower- and upper-level clouds were defined by the cloud top pressure to be above and below $600 \mathrm{hPa}$, respectively (an altitude of approximately $4 \mathrm{~km}$ ). Numbers in brackets indicate the percentages (\%) of the total number of observations in each category.

\begin{tabular}{lccccc}
\hline Period & Upper cloud & Lower cloud & Upper and lower & Clear & Total \\
\hline July 18-28 & 11 & 5 & 5 & 0 & 21 \\
August 12-19 & 10 & 2 & 3 & 2 & 17 \\
\hline Total & $21(55.3)$ & $7(18.4)$ & $8(21.0)$ & $2(5.3)$ & 38 \\
\hline
\end{tabular}

and basins) and other processes on the formation of the upper-level cloud has yet to be investigated and is beyond the scope of the present study.

The next two subsections consider the Yamase clouds that developed in July and August (the mature stage of a Yamase event). The cloud that developed prior to the Yamase event is also described to aid our understanding of the characteristics of the Yamase cloud.

3.3. Yamase Cloud Case I: July 22. We here describe the typical properties of the Yamase cloud at the end of July. Figure 2(a) shows the vertical velocity and horizontal wind patterns at $975 \mathrm{hPa}$ at 0300 UTC July 22 (equivalent to 1200 UTC July 22 according to Japan Standard Time (JST); the time difference between UTC and JST is $+9 \mathrm{~h}$ ). A northeasterly wind was blowing in coastal areas, which caused increased upward wind velocities along the coast. In contrast, the easterly and southeasterly wind velocities and the downward velocity were higher to the west of the $\mathrm{Ou}$ Mountain chain (inland of Sanriku).

Figures 3(a) and 3(b) show that cloud tops were located between 900 and $650 \mathrm{hPa}(1-3 \mathrm{~km})$. Three peaks, at 880 , 750 , and $670 \mathrm{hPa}$, occur over land (red line), and two peaks occur over ocean (blue line). The peak at $670 \mathrm{hPa}$ over land (greenish shading, Figure 3(a)) represents the cloud top pressure over the Kitakami basin, located between the Kitakami and $\mathrm{Ou}$ Mountains. No significant gaps along the coastline are present, and the cloud top pressure (height) decreased (increased) slightly toward inland areas. In contrast, to the east of the Tohoku area, a clear region and a low-level cloud spread to the west side of the Ou Mountains (west of the Tohoku area).

Figure 2(b) shows temperature and $\mathrm{RH}$ profiles at Misawa from the surface to an altitude of $6 \mathrm{~km}$ at 0000 UTC $(0900$ JST). The radiosonde observations were obtained twice daily (at 0000 and 1200 UTC) at Misawa. The temperature and RH profiles show that the cloud top was located at approximately $750 \mathrm{hPa}$ (approximately $2.8 \mathrm{~km}$ ), a temperature inversion layer was located at approximately $700 \mathrm{hPa}$ (approximately $3 \mathrm{~km}$ ), and a region of high $\mathrm{RH}$ extended to just above $800 \mathrm{hPa}$ (approximately $2 \mathrm{~km}$ ). The Yamase cloud top was generally at a height of $1-2 \mathrm{~km}$, with precipitation and misty rain absent; however, the cloud top in this case was higher than that of the normal Yamase cloud (but less than $3 \mathrm{~km}$ ). In this case, no rain was recorded by ground-based observations.

Figures 4(a) and 4(b) show the horizontal distribution of $r_{e}$. As described in Section 2, the $r_{e}$ values retrieved by the $2.13 \mu \mathrm{m}$ MODIS channel are from the middle layer of the cloud. The $r_{e}$ values show distinct differences between values over land and ocean/coastal regions (in contrast to cloud top distributions). Values of $r_{e}$ over ocean and coastal regions were larger than those over land, and values varied widely (from 5 to $20 \mu \mathrm{m}$ ) and were bimodal ( 10 and $18 \mu \mathrm{m}$ ). Values of $r_{e}$ over land were mainly between 5 and $10 \mu \mathrm{m}$. The longitudinal distribution of $r_{e}$ averaged $39^{\circ} \mathrm{N}-40^{\circ} \mathrm{N}$ (not shown), indicating that the maximum value was $15 \mu \mathrm{m}$ at the coastal region; $r_{e}$ values decreased rapidly to $10 \mu \mathrm{m}$, while on the east side (ocean), $r_{e}$ values decreased gradually to $12 \mu \mathrm{m}$.

The distribution of $\tau$ (Figure 5 ) shows a clear distinction between land and ocean, with optical thicknesses over land being greater and more variable than those over ocean. Values of $\tau$ over ocean were less than 10 , while values over land were between 10 and 20. High values over land were located in coastal areas and topographic basins; that is, windward (east) sides of mountains tend to generate greater optical thicknesses. The geometric thickness of the Yamase cloud in this case was large (several kilometers), as represented by the $\mathrm{RH}$ profile obtained from sonde observations (Figure 2(b)); however, around Misawa, optical thicknesses were relatively small (less than 10).

3.4. Yamase Cloud Case II: August 16. Figure 6(a) shows map of the vertical velocity and horizontal wind pattern associated with Yamase cloud formation in mid-August. The horizontal wind was northeasterly at Sanriku and easterly in the Tohoku area. As shown in Figure 2 (Case I), the upward velocity at the coast and east of the $\mathrm{Ou}$ and Kitakami Mountains and the downward motion on the west side of the Ou Mountain chain. At this time, the cloud top pressure was between 600 and $900 \mathrm{hPa}$ (Figure 7). Figure 6(b) shows that the cloud top at Misawa was at $900-800 \mathrm{hPa}$. No rain was recorded by the ground-based network.

Values of $r_{e}$ were successfully retrieved over ocean, coastal areas, and some land areas, such as leeward of mountains (Figure 8). The tendency of $r_{e}$ was nearly the same as that in Case I; that is, the average value of $r_{e}$ over land was less than that over the ocean, and the range of $r_{e}$ values over ocean was greater than that over land. The average $r_{e}$ over land was greater in Case II than in Case I; modal values of $r_{e}$ in Cases $I$ and $I I$ were 8 and $11 \mu \mathrm{m}$, respectively. The longitudinal distribution of $r_{e}$ averaged between $39^{\circ} \mathrm{N}$ and $40^{\circ} \mathrm{N}$ (not shown) shows that the maximum value of $r_{e}$ in coastal regions was $15 \mu \mathrm{m}$. On the landward side, $r_{e}$ decreased gradually to $10 \mu \mathrm{m}$, while on the ocean side, $r_{e}$ decreased only slightly (to $13 \mu \mathrm{m}$ ). The distribution of $\tau$ values (see Figure 9) is similar to that in Case $I$; that is, $\tau$ values over land were greater than those over ocean, and the area of large $\tau$ extended over land, especially east of the mountains. 


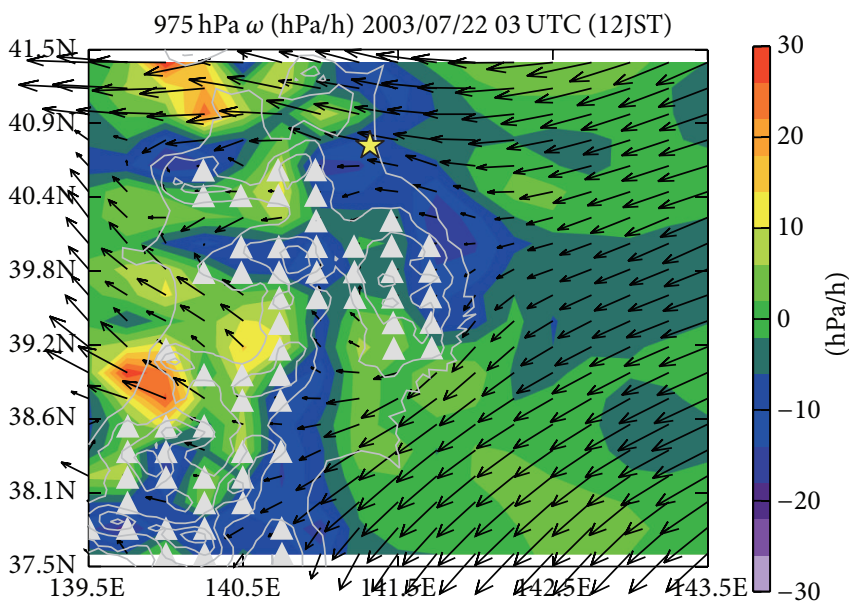

(a)

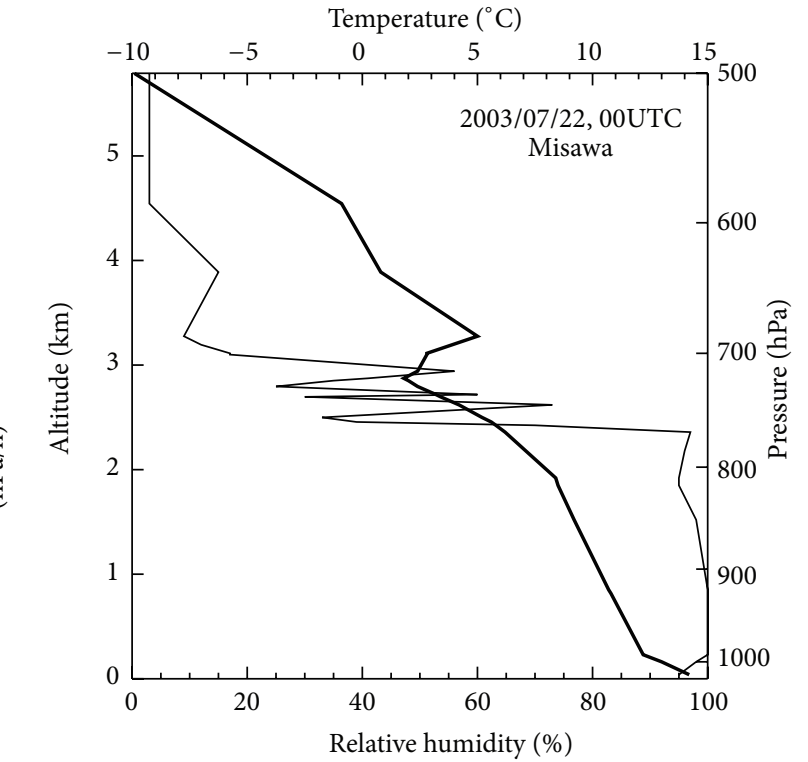

(b)

FIGURE 2: (a) Map of vertical wind velocity ( $\omega, \mathrm{hPa} / \mathrm{h}$, and color shading) and horizontal wind vectors at $975 \mathrm{hPa}$ at $0000 \mathrm{UTC}$ July 22,2003 . The white contour lines on land show elevations (contour interval, $300 \mathrm{~m}$ ); white triangles indicate the locations of mountains with equivalent heights greater than $975 \mathrm{hPa}$; latitude and longitude resolution, 0.5 degrees. The star shows the location of Misawa $\left(141.38^{\circ} \mathrm{E}, 40.7^{\circ} \mathrm{N}\right) .(\mathrm{b})$ Vertical profiles of temperature (K; thick lines) and relative humidity (\%; thin lines) at Misawa at 0000 UTC July 22, 2003.

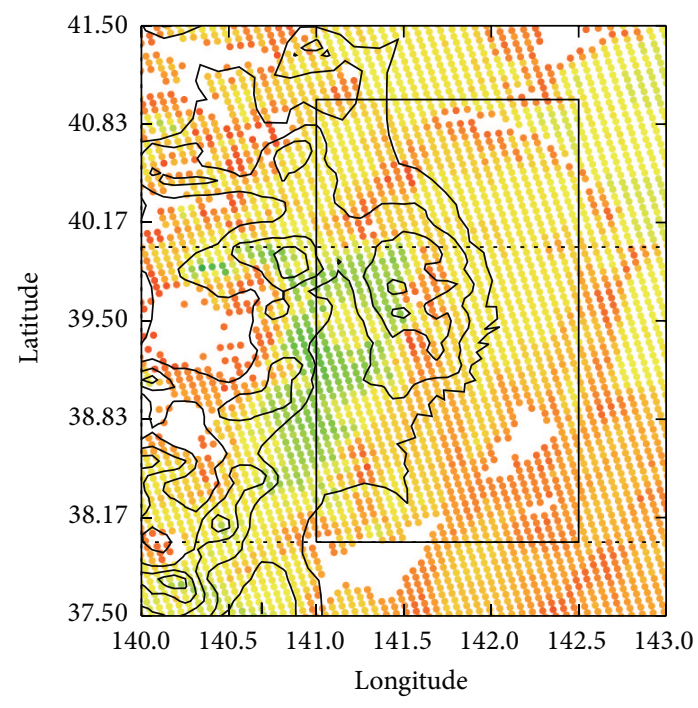

(a)

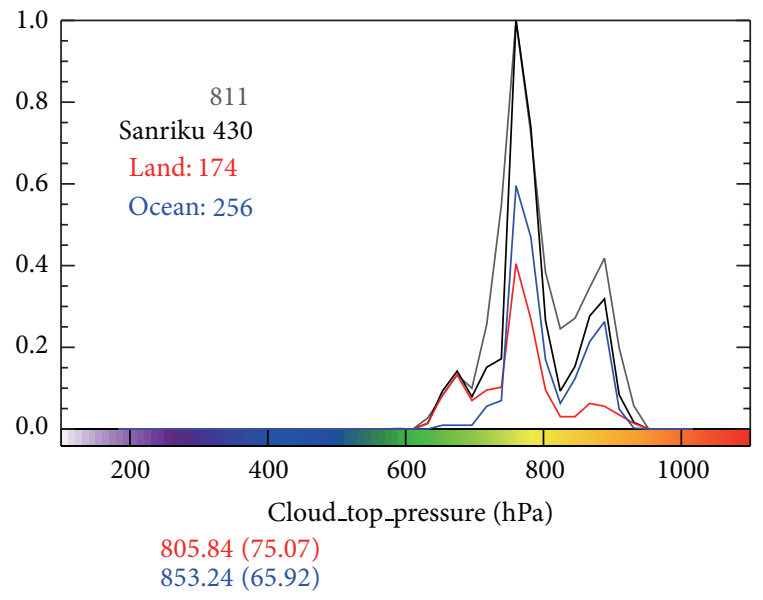

(b)

FIGURE 3: (a) Map of cloud top pressures [hPa] and (b) cloud top pressures normalized by the maximum value in the Sanriku region (black box in (a)) over the northern part of the main island of Japan, at approximately 0345 UTC July 22, 2003. The color shading indicates cloud top pressures according to the color bar in (b). The shading in (b) (grey, black, red, and blue) indicates maximum values over the entire swath, the Sanriku area, the land area, and the oceanic area in Sanriku, respectively. The values at the bottom of (b) show the averages and standard deviations (in brackets) for land (red) and ocean (blue) in the Sanriku area.

Some features of Case II are similar to those of Case I; however, in addition to larger values of $r_{e}$ over land in Case $I$, the differences under the different synoptic meteorological condition include the height of the cloud top located below $600 \mathrm{hPa}$, which was relatively higher over land than over ocean, and the absence of cloud on the west side of the Tohoku area (the west side of the Ou Mountain chain).

3.5. Yamase Cloud Case III: July 16. Having described the typical features of the Yamase cloud, this subsection presents 


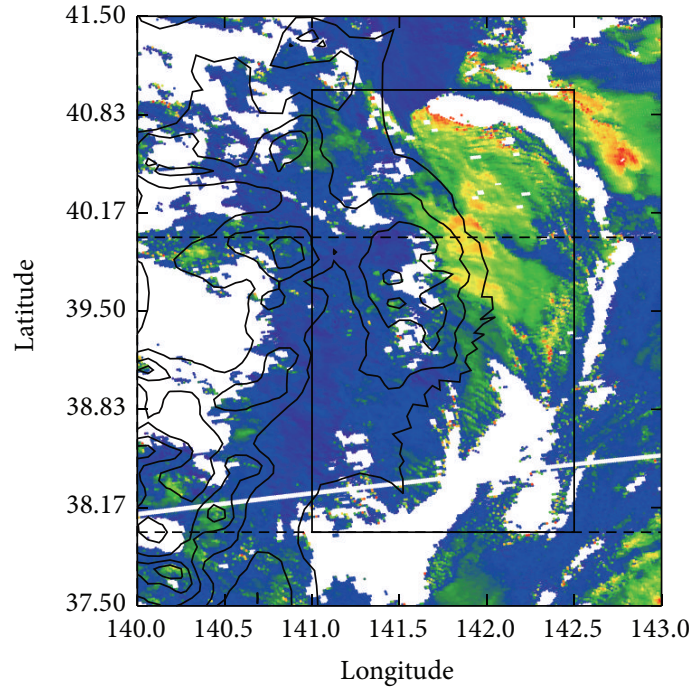

(a)

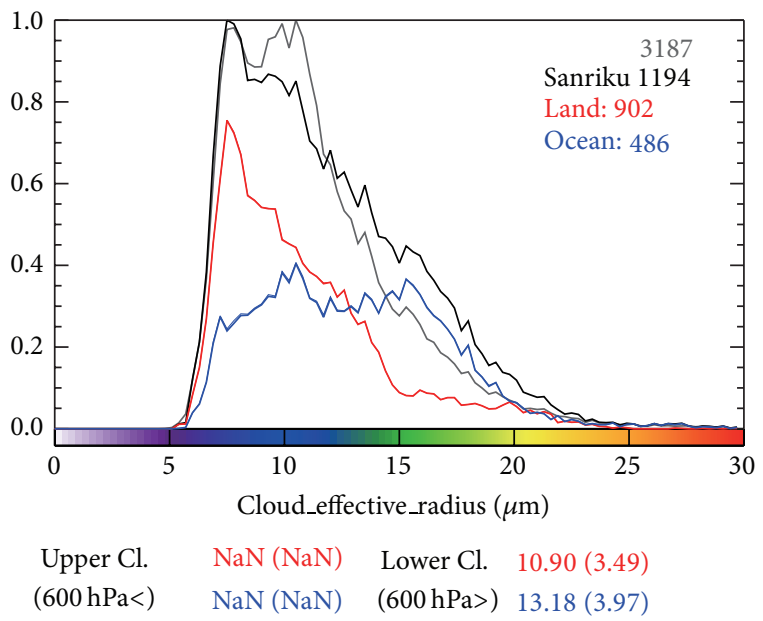

(b)

Figure 4: Same as Figure 3 but for effective cloud radius $\left(r_{e}\right)$. The values in (b) indicate maximum values in each category (whole swath, Sanriku area (black box in (a)), and land and ocean in the Sanriku area). The values at the bottom of (b) show averages and standard deviations (in brackets) of the upper and lower clouds for land (red) and ocean (blue) in the Sanriku area.

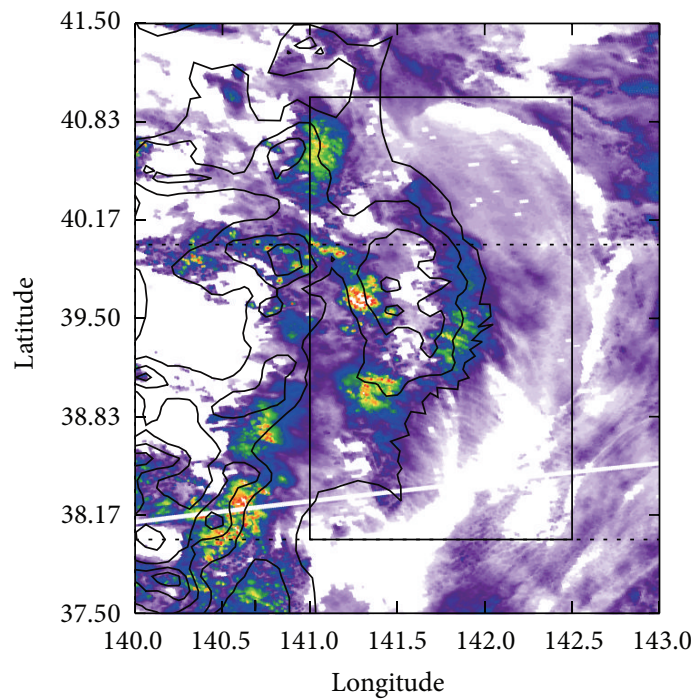

(a)

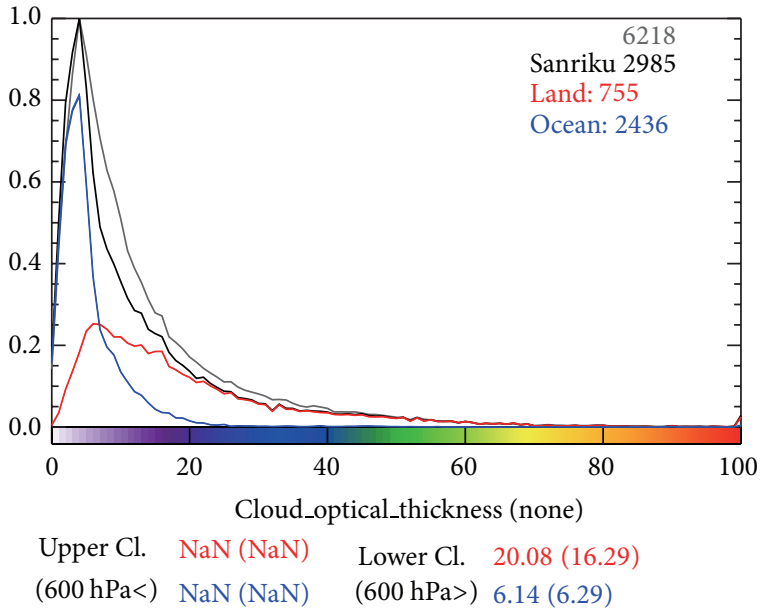

(b)

FIgURE 5: Same as Figure 4 but for cloud optical thickness $(\tau)$.

the unique features of the cloud that developed in the period immediately prior to the mature phase of the Yamase event, with the aim of improving our understanding of the Yamase cloud and its characteristics.

Figure 10(a) shows the wind field on July 16; easterly and westerly winds are present on the east and west sides of Tohoku, respectively. The horizontal wind field caused convergence over the land and enhanced upward velocities, especially on the windward side of the mountains. During this period, the temperature inversion layer was not clearly defined (Figure 10(b)), but RH was high (greater than $80 \%$ ) up to $700 \mathrm{hPa}$ (approximately $3 \mathrm{~km}$ ).

The differences between cloud top pressures over land and ocean are clearly observed in Figure 11, the cloud top over land being approximately $1 \mathrm{~km}$ higher than that over the ocean. This land-ocean contrast is also observed in the $r_{e}$ values (Figure 12), with $r_{e}$ values over land being larger than those over ocean, which contrasts with the Yamase cloud situations in Cases I and II; that is, modes of the $r_{e}$ distribution were approximately $15 \mu \mathrm{m}$ over land and $9 \mu \mathrm{m}$ 


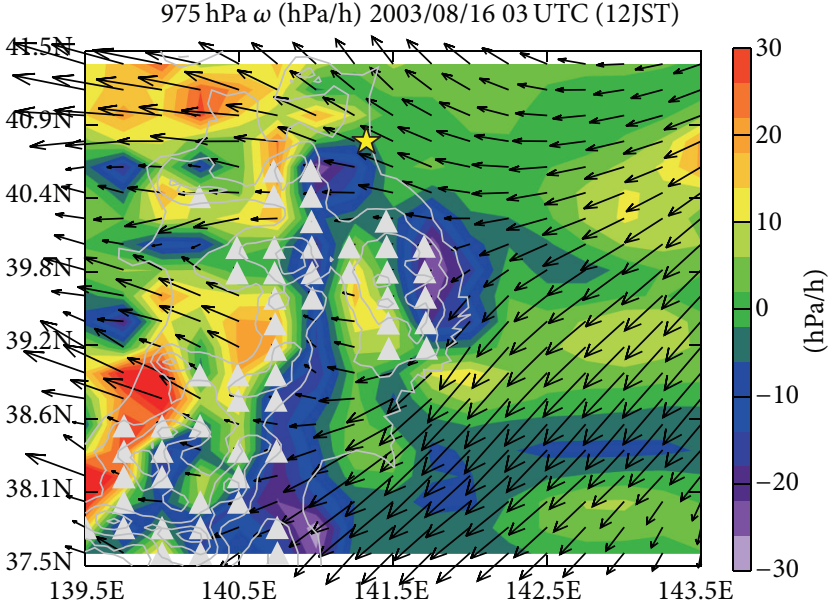

(a)

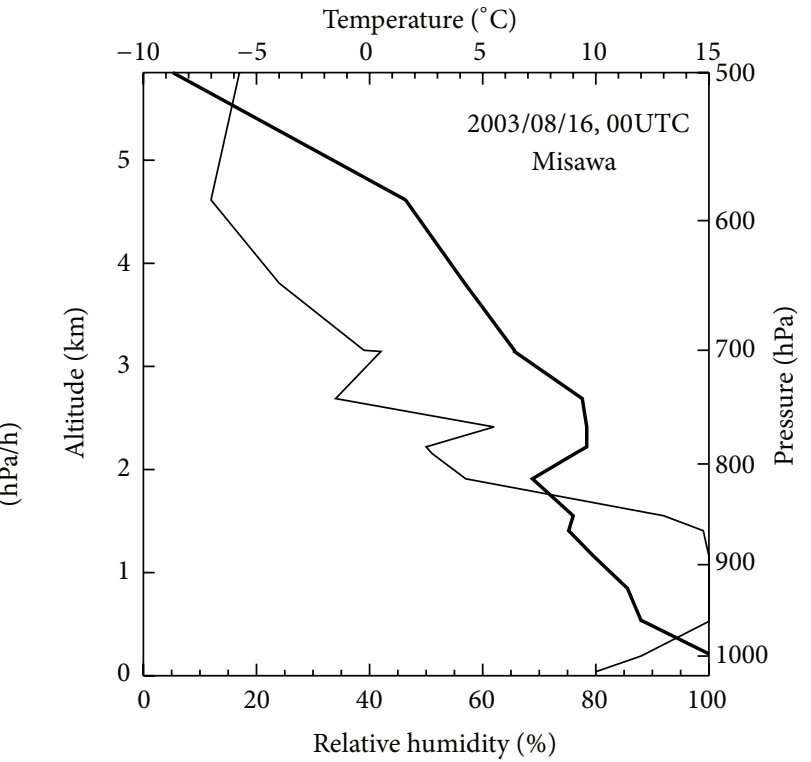

(b)

FIGURE 6: Same as Figure 2 but at 0335 UTC August 16, 2003.

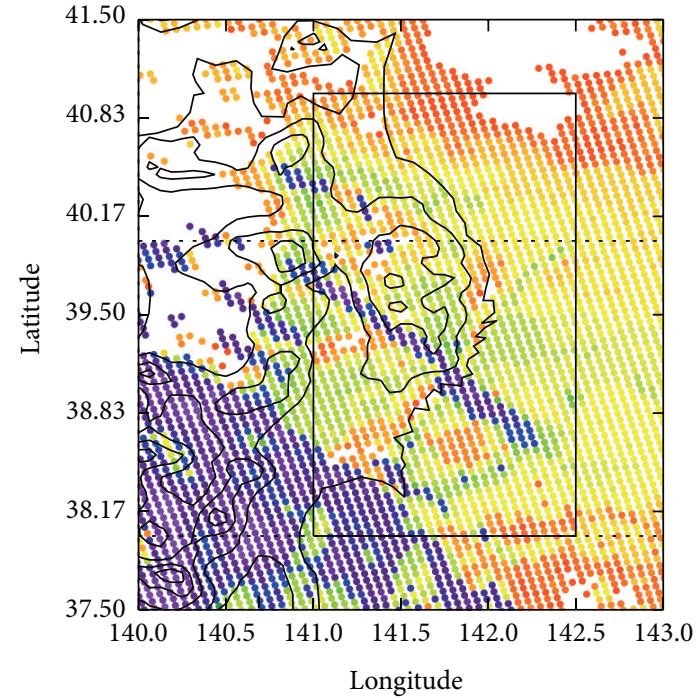

(a)

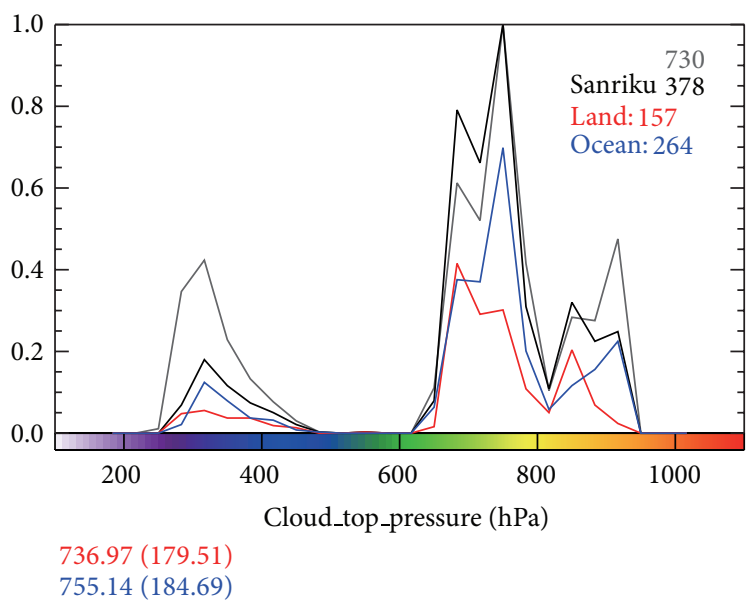

(b)

FIgURE 7: Same as Figure 3 but at 0335 UTC August 16, 2003.

over ocean (as compared with 11 (12) $\mu \mathrm{m}$ and 13 (14) $\mu \mathrm{m}$ in Cases $I$ and $I I$, resp.).

In contrast, $\tau$ values observed during the pre-Yamase period were similar to those observed during the mature Yamase phase (Figure 13), with $\tau$ values over land being greater than those over the ocean. Precipitation was limited (less than a few millimeters per hour) during the period before the Yamase event, which is similar to precipitation patterns observed during the Yamase mature period. The cloud covering Tohoku during the pre-Yamase period (1517 July) was nonconvective, because of relatively reduced precipitation and a lowered cloud top height. Thus, in the developing stage, a convection-like cloud forms (but without heavy precipitation; figure is not shown), and $r_{e}$ values near the cloud top tend to be large. It is possible that opposing features of the cloud properties in pre-Yamase versus mature Yamase periods (in terms of cloud top heights and $r_{e}$ values) were caused by the convection-like cloud generated by the convergent properties of the wind field.

3.6. Brief Summary of Yamase Cloud Properties. Figure 14 summarizes the different properties associated with 


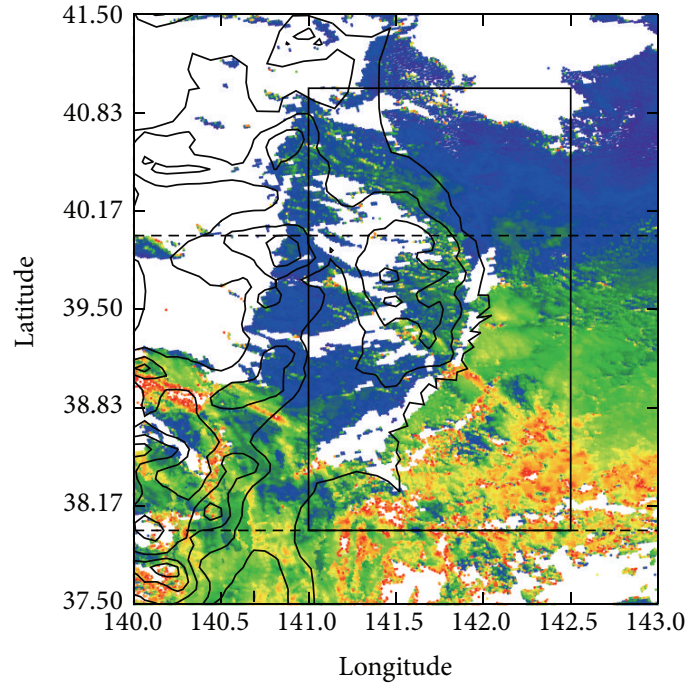

(a)

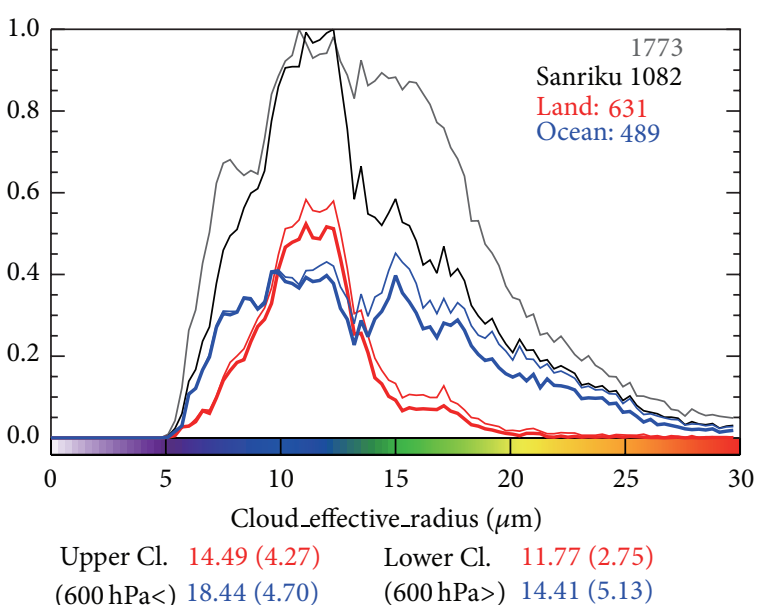

(b)

FIgURE 8: Same as Figure 4 but at 0335 UTC August 16, 2003. The thick (thin) red and blue lines indicate the distributions of the lower (upper) cloud over land and ocean, respectively.

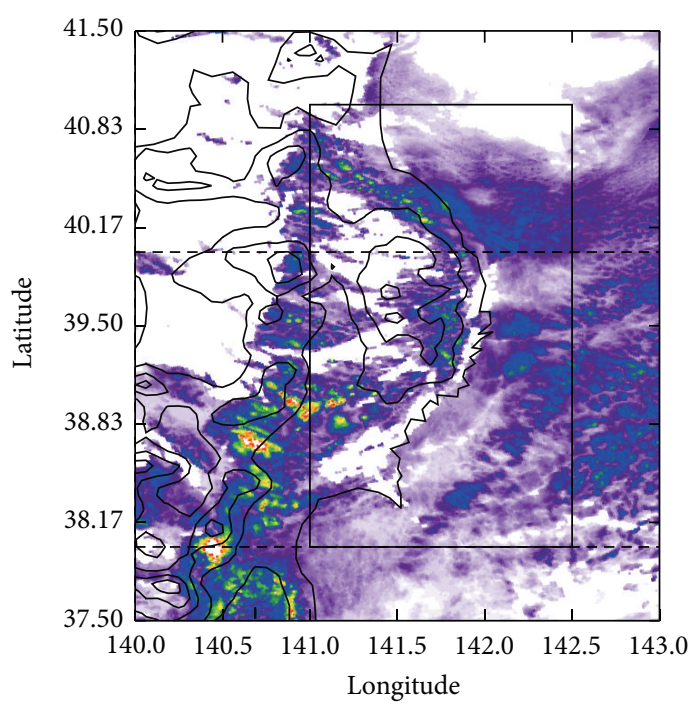

(a)

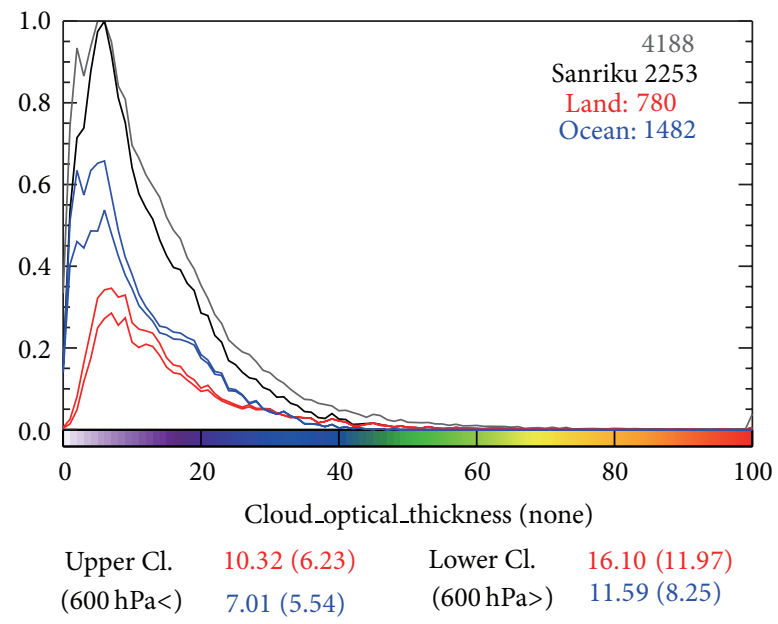

(b)

FIGURE 9: Same as Figure 8 but for cloud optical thickness $(\tau)$.

he Yamase cloud over land and ocean based on the 12 cases observed by MODIS during the two study periods. First, it is apparent that any variability in the observations related to either the measurement period (July versus August) or the local time of observation (morning versus afternoon) is considerably less significant than that related to the land-ocean contrast.

The cloud top pressure ranged from 900 to $700 \mathrm{hPa}(1-$ $3 \mathrm{~km}$ ), with variations over both land and ocean of approximately $100 \mathrm{hPa}$. Cloud top pressures over land and ocean were similar (within a few tens hPa) and were in good agreement with the inversion layer as determined by in situ vertical temperature profiles. The average cloud top pressures of the 12 cases over land and ocean were 813.3 and $818.2 \mathrm{hPa}$, respectively, and the spatial variations in the Yamase area over land and ocean were nearly the same ( 41.5 and $51.1 \mathrm{hPa}$, resp.).

The scatter plot of $r_{e}$ values shows that values over land were smaller than those over the ocean; the averages and standard deviations (STDs) of the $r_{e}$ values over land and ocean were 11.8 (3.1) and $13.5(2.1) \mu \mathrm{m}$, respectively. A few cases that showed relatively large $r_{e}$ values over land were associated with data sets that were small (relative to the other data sets), which are reflected in the relatively large STDs (spatial variation). The spatial variations in the analysis area 


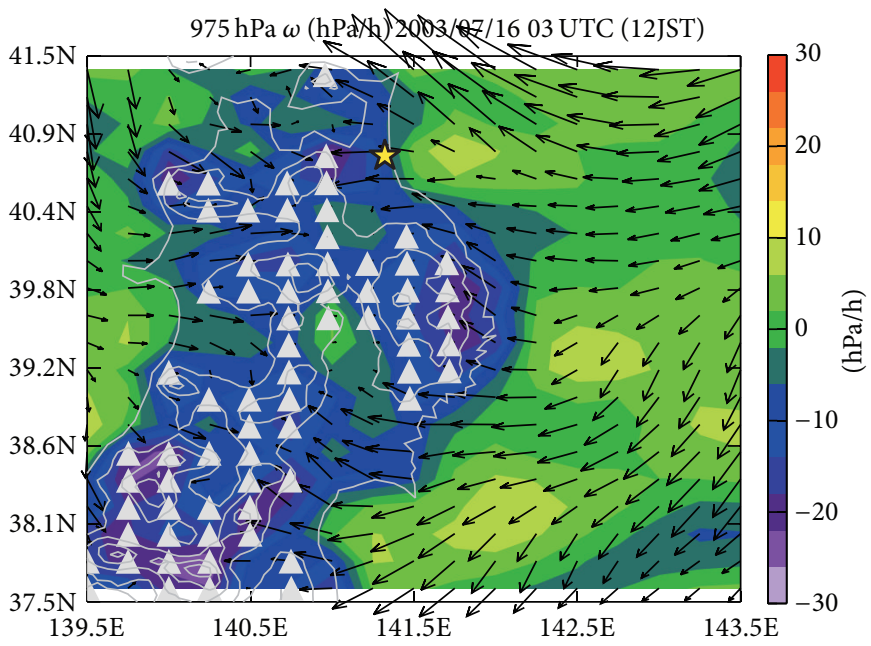

(a)

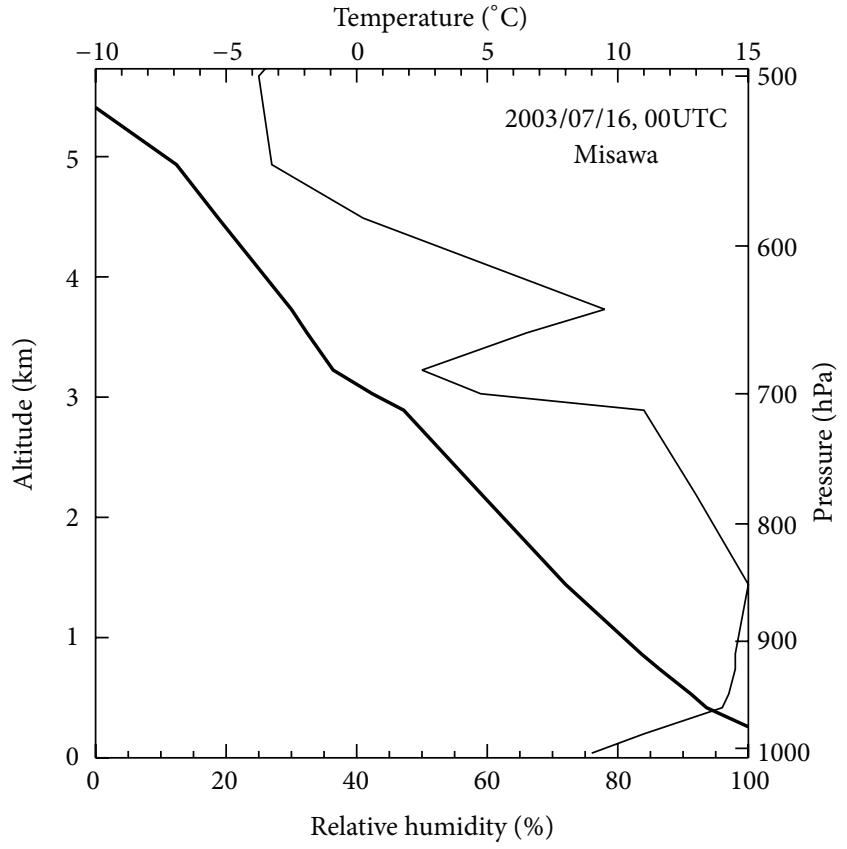

(b)

FIgUre 10: Same as Figure 2 but at 0150 UTC July 16, 2003.

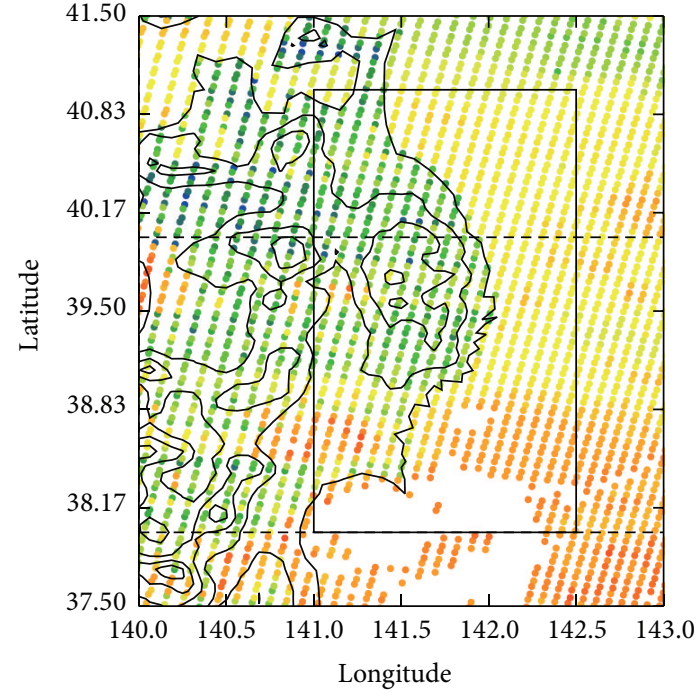

(a)

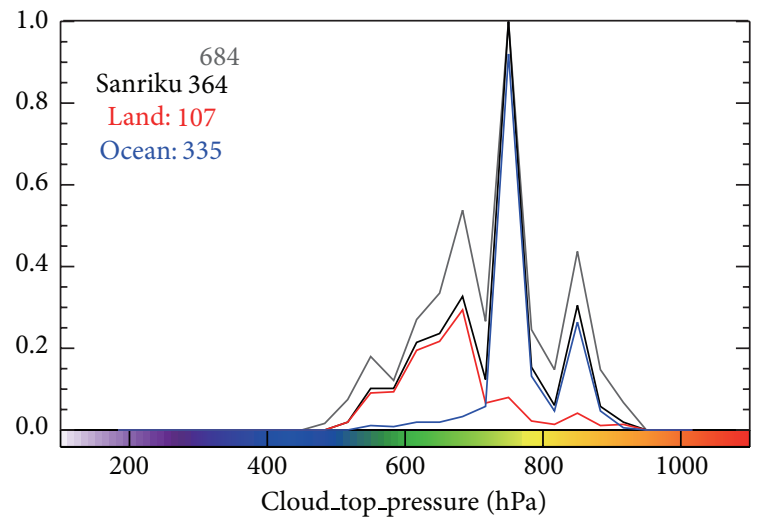

$693.73(92.52)$ $814.75(70.27)$

(b)

FIgURE 11: Same as Figure 3 but at 0150 UTC July 16, 2003.

for each case show that heterogeneities over the ocean were greater than those over land, especially in areas where $r_{e}$ values were less than $15 \mu \mathrm{m}$.

In contrast to $r_{e}$ values, the $\tau$ and cloud water path values over land were larger than those over the ocean, and the spatial homogeneity over land was less than that over ocean. The averages (and STDs) of $\tau$ values over land and ocean were 19.6 (4.6) and 10.3 (5.6), respectively, and the cloud water path was $70-200 \mathrm{~g} \mathrm{~m}^{-2}$ (mean/STD: $145 / 33 \mathrm{~g} \mathrm{~m}^{-2}$ ) over land and $25-200 \mathrm{~g} \mathrm{~m}^{-2}\left(86 / 43 \mathrm{~g} \mathrm{~m}^{-2}\right)$ over ocean. The spatial variations (error bars) associated with $\tau$ were 12.3 over land and 6.8 over ocean, and the spatial variations of the cloud water path were $100 \mathrm{~g} \mathrm{~m}^{-2}$ over land and $61 \mathrm{~g} \mathrm{~m}^{-2}$ over ocean. Figure 14 suggests that the cloud droplet number over land is greater than that over ocean, assuming the same cloud water paths values.

The averaged properties of the meteorological fields (wind fields, temperature, relative humidity, etc.) for the 12 


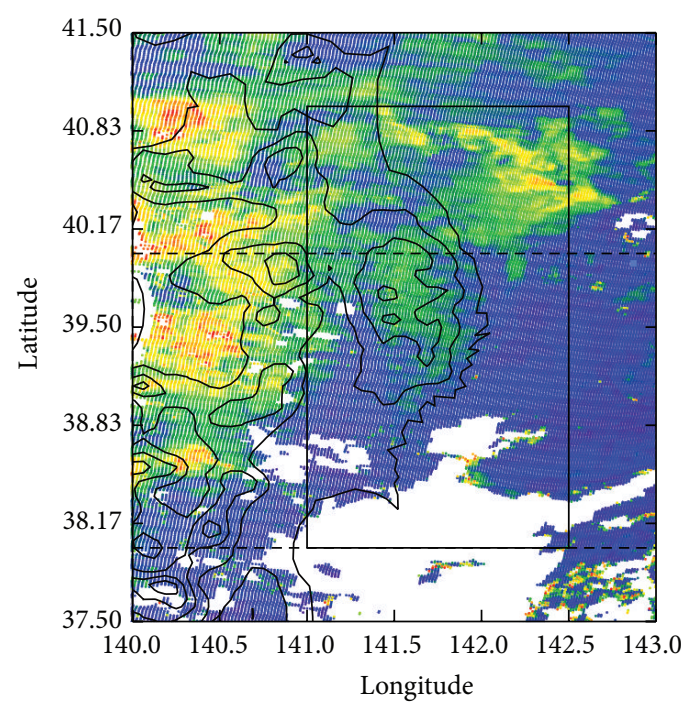

(a)

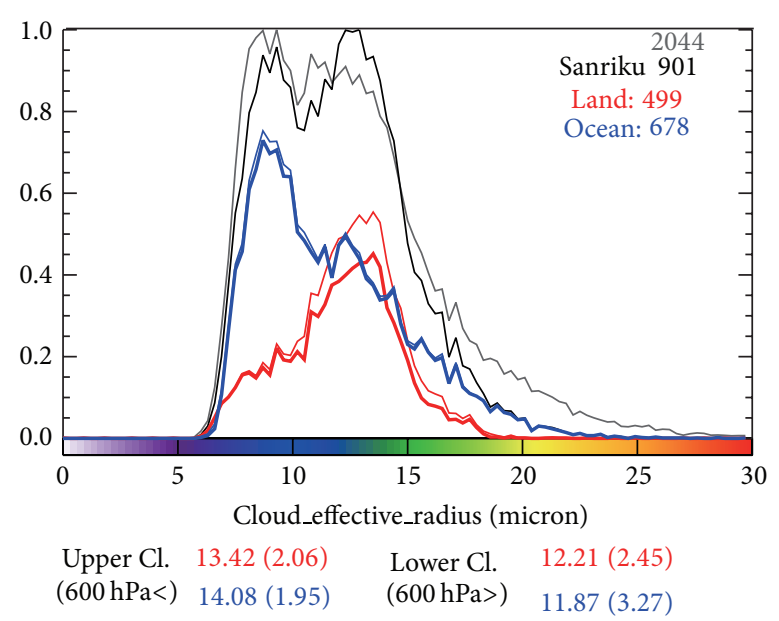

(b)

Figure 12: Same as Figure 8 but at 0150 UTC July 16, 2003.

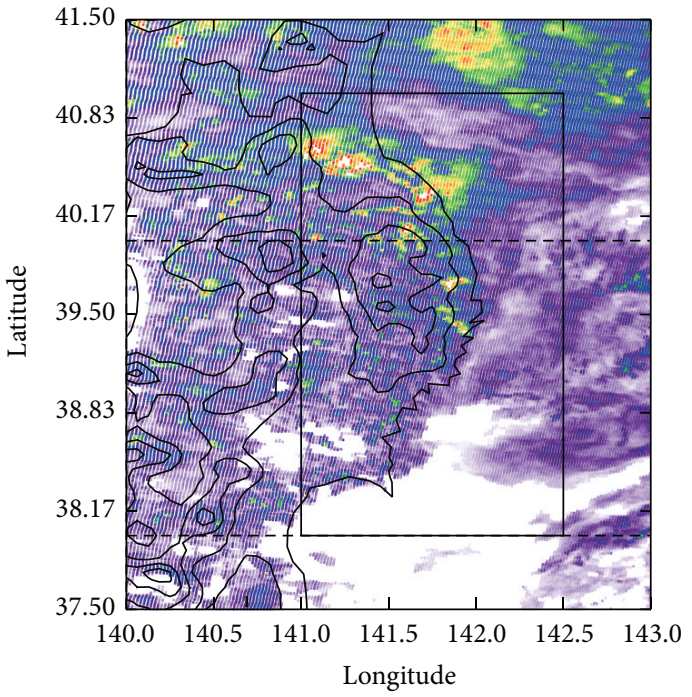

(a)

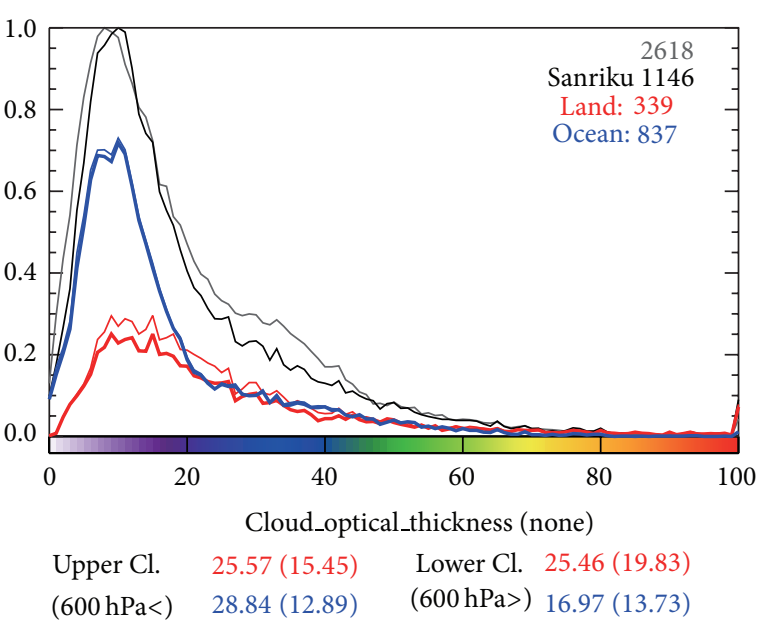

(b)

FIgURE 13: Same as Figure 9 but at 0150 UTC July 16, 2003.

Yamase cloud cases (figures are not shown) yielded vertical pressure velocities $(\omega)$ of less than $800 \mathrm{hPa}$ (corresponding to averaged cloud top heights and showing contrasting maritime-continental features) and negative $\omega$ values (upward) over land, with maximum values occurring near the surface (approximately $8 \mathrm{hPa} / \mathrm{h}$ ) and being higher over land than over ocean $( \pm 2 \mathrm{hPa} / \mathrm{h})$.

The average values of each parameter obtained in the present study are fairly consistent with the results presented in [4], although in the present study values of $r_{e}$ obtained over the ocean were slightly larger than those obtained in [4]. A comparison of the lower cloud characteristics determined in this study with values representing global and annual means determined by AVHRR/NOAA [7] shows that the $r_{e}$ values obtained in this study are approximately $1 \mu \mathrm{m}$ less and $\tau$ values are approximately twice as large over both land and ocean. The $1 \mu \mathrm{m}$ difference in $r_{e}$ values is within the level of uncertainty associated with the data retrieval method, but the larger $\tau$ values suggest that the Yamase cloud is optically thick as compared with stratus clouds in general. In summary, the Yamase cloud has a greater optical thickness than do general stratus clouds and is also spatially and temporally inhomogeneous over land; in addition, the Yamase cloud possesses characteristics which are distinct from those of the pre-Yamase period cloud. These features lead to complex radiation impacts at the surface.

In addition, the Yamase cloud parameters showed strong land-ocean/coastal region contrasts. Our results show that 


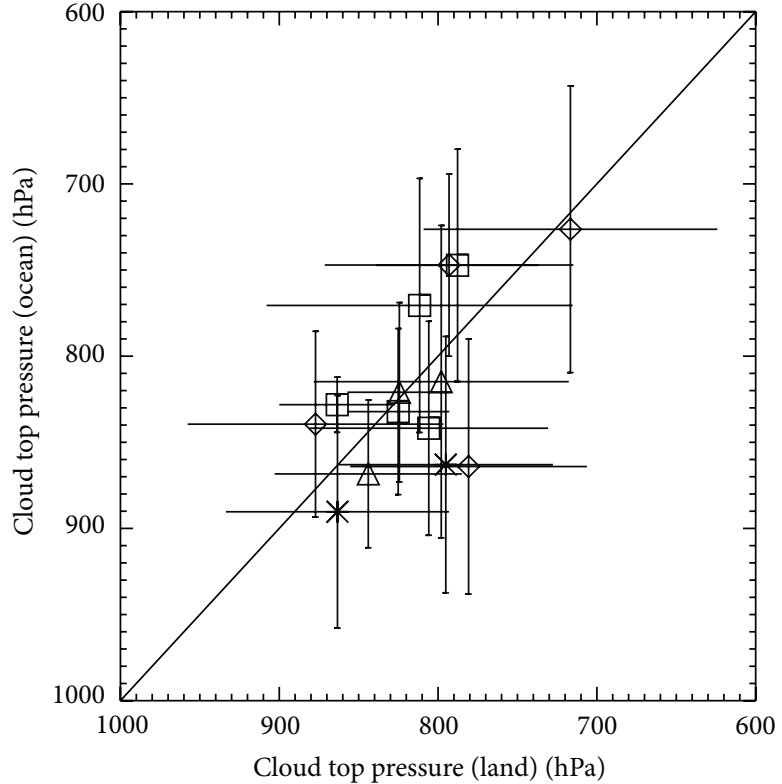

(a)

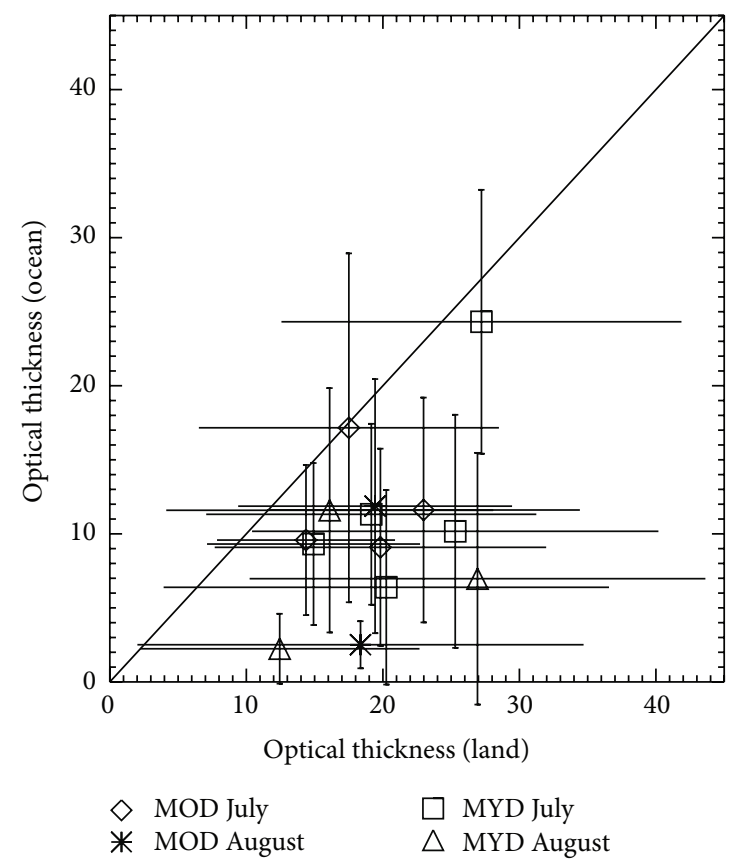

(c)

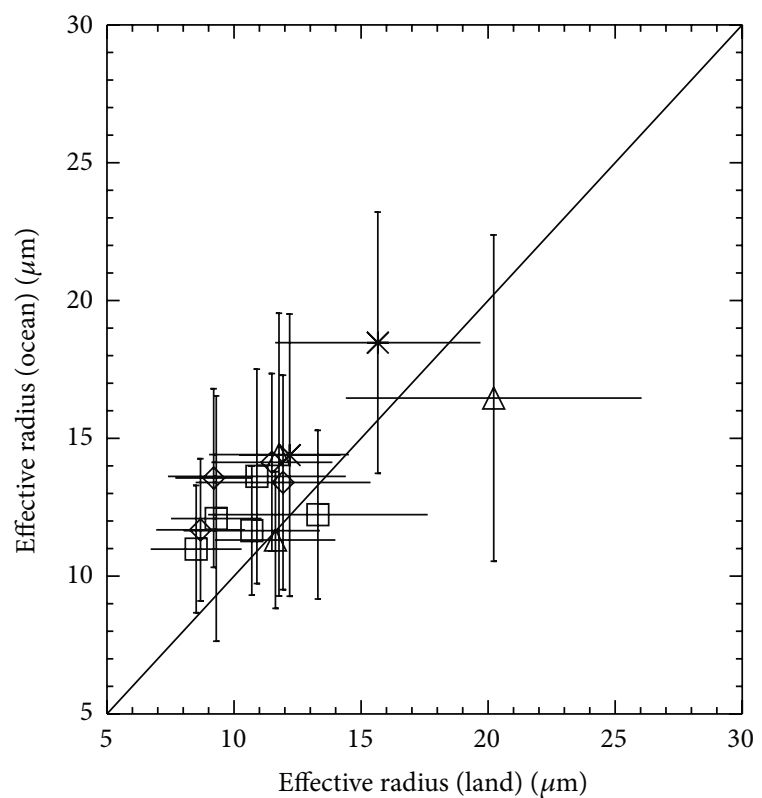

(b)

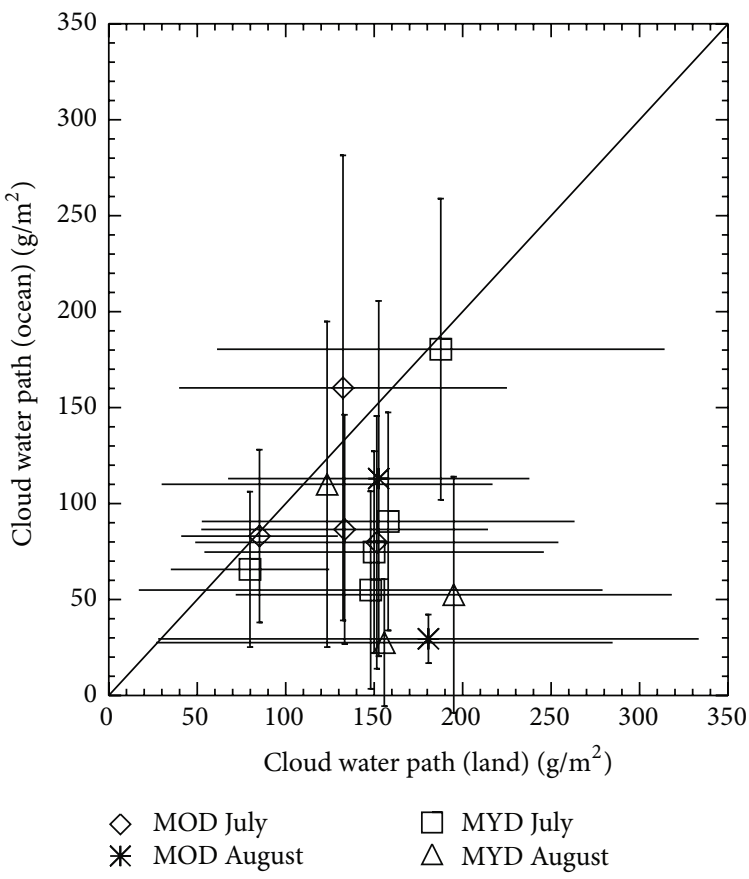

(d)

FIGURE 14: Scatter plots of cloud top pressure (a), effective radius $\left(r_{e}\right)(\mathrm{b})$, optical thickness $(\tau)(\mathrm{c})$, and cloud water path (d) over land and ocean based on the 12 cases of lower-level cloud in the two periods (end of July and middle of August) detected by the MODIS onboard the Terra and Aqua satellites. One-to-one lines are also plotted. Horizontal and vertical bars indicate standard deviations $(1 \sigma)$ of each parameter over land and ocean in the Sanriku area (black box, Figure 3(a)), respectively. Explanations of symbols are as shown in (a).

the $\tau\left(r_{e}\right)$ values of the Yamase cloud are inhomogeneous in nature over land (ocean), with less variability over ocean (land) than over land (ocean). The properties of the Yamase cloud change once the cloud reaches land; the properties change gradually from the coastline to inland areas, and transition zones exist for all properties in the coastal region (e.g., Figure 4).

\section{Discussion}

Here, we further investigate the land-ocean contrast of Yamase cloud parameters. In general, the main factors that cause differences in the values of cloud parameters between land and ocean are aerosol characteristics and vertical motions (stability), both of which influence 


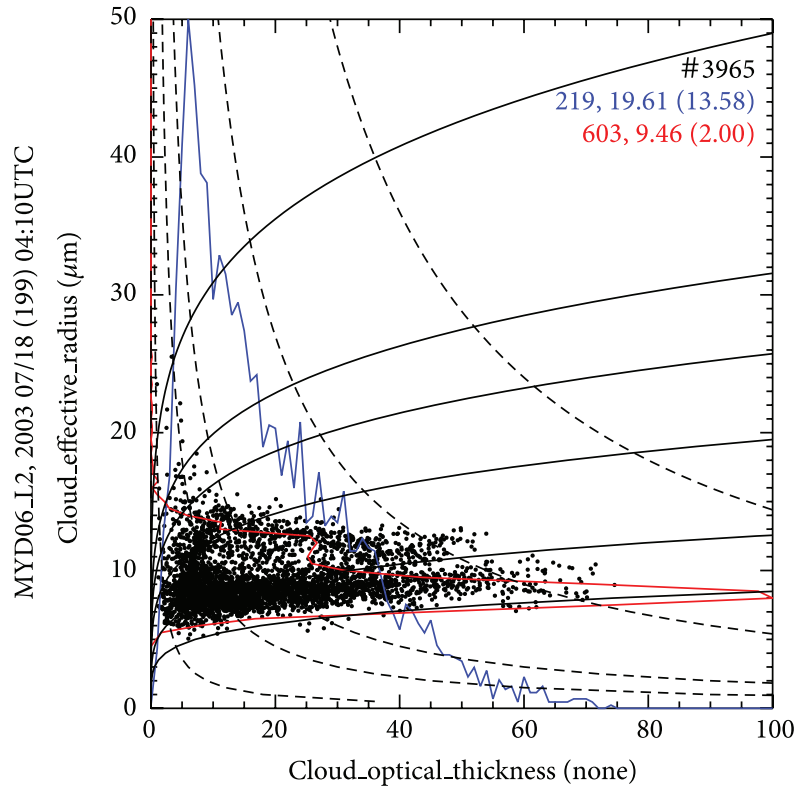

(a) Land, low Cl. (>600 hPa)

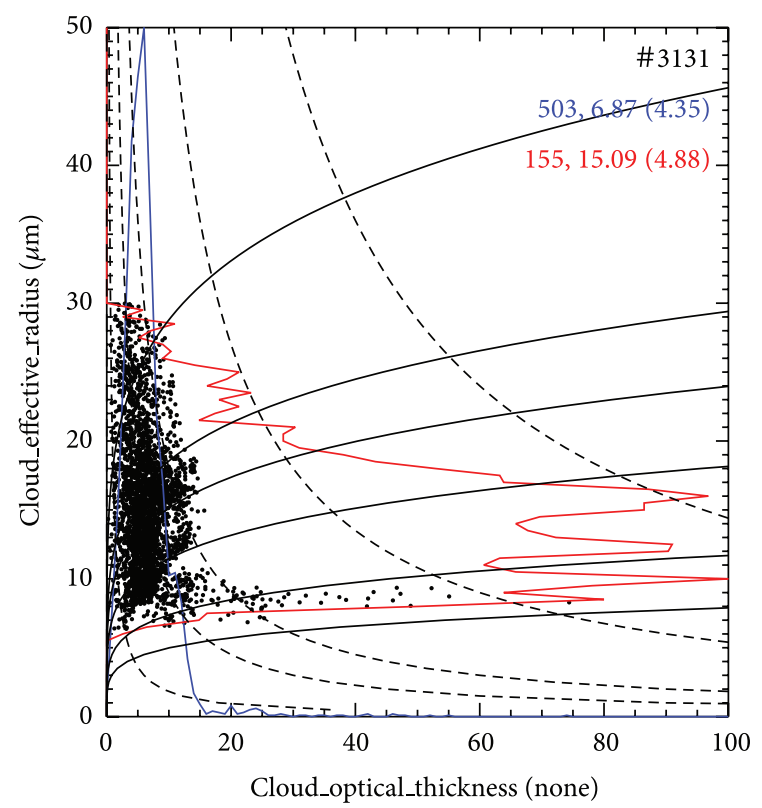

(b) Ocean, low Cl. $(>600 \mathrm{hPa})$

FIGURE 15: Scatter plots of optical thickness $(\tau)$ and effective radius $\left(r_{e}\right)$ of lower-level cloud over land (a) and ocean (b) in the analysis area at 0410 UTC July 19, 2003. The blue (red) line represents a normalized histogram of $\tau\left(r_{e}\right)$. The values in the panels represent the numbers of observations, the maximum values in the histograms, and the averages and standard deviations of $\tau$ (blue) and $r_{e}$ (red). The solid lines show the cloud droplet number concentration (from top to bottom): 10, 30, 50, 100,300, and $800\left[\mathrm{~cm}^{-3}\right]$, and the dashed lines show the liquid water path (from bottom to top): 10, 50, 100, 300, and $800\left[\mathrm{~g} \mathrm{~m}^{-2}\right]$ calculated using (12) and (13) of [23], respectively.

the characteristics of stratus clouds, as has been discussed elsewhere [5-7, 23].

Aerosol effects were examined using MODIS aerosol products (MOD04/MYD04), which provide parameters such as aerosol optical depth (AOD) and the fine-mode (submicron size) fraction concentration but only over areas with small cloud fractions [24-26]. Although the MODIS aerosol data were limited to cloud-free pixels, the aerosol information obtained during the analysis period was informative. The aerosol data, derived from less than 20 cases of cloudless area occurring between July 15 and August 20, revealed the following aerosol features over the Yamase area. First, the differences in aerosol parameters among the stages of Yamase development (pre-, developing, and mature phases) were not clear. No significant differences were observed between the AOD over land and ocean (values varied in the range of $0.2-$ 0.7; not shown). The AOD of the fine-mode fraction over land was typically close to, or equal to, 1.0 for all cases, while the fraction over ocean was approximately 0.5 and decreased from the coastline seaward. We suggest that the aerosol over land was composed of smaller particles, such as sulfates and carbonates, while aerosol near the coast was a mixture of fine and coarse particles (e.g., sea salt), and aerosol over oceans consisted of relatively coarse particles.

Aerosol information from the Spectral RadiationTransport Model for Aerosol Species (SPRINTARS) [27, 28] indicates that, in the study area, sulfate and organic matter were dominant over land surfaces, whereas sea salt was dominant over ocean surfaces during the analysis period (http://sprintars.riam.kyushu-u.ac.jp/archivej.html). Aerosols impact the microphysical characteristics of clouds. Large concentrations of aerosols cause an increase in the availability of cloud condensation nuclei (CCN), an increase in the optical thickness of the cloud, a lower supersaturation [29], and a reduced precipitation (a tendency towards nondrizzling) [30]. The results of the present study indicate that the differences between the characteristics of the Yamase cloud over land and ocean are the same as those of general stratus clouds.

An additional influence on cloud parameters is related to dynamical effects, such as vertical motion and stability (e.g., [31]). The Kitakami Mountains, which are near the east coast of the Sanriku region, have a marked impact on the direction of the Yamase wind, mainly forcing it upwards; this adiabatic upward motion causes an increase in cloud water content under a continuous supply of water vapor. As a result, $\tau$ increases along coastal areas, as shown in Figures 5(a) and 9(a). In addition, the complex topography amplifies the inhomogeneous distribution of cloud properties over land.

The relationship between $\tau$ and $r_{e}$ indicates the developmental stage of the cloud, the status as drizzling or nondrizzling [5, 32, 33], aerosol effects (polluted or clean air), and the stability of the atmosphere with respect to the microphysical properties of the cloud [23]. Figures 15 and 16 show scatter plots of $\tau$ and $r_{e}$ at the beginning and mature stages of Yamase development, respectively. The curved solid and dashed lines in Figures 15 and 16 are the cloud droplet number concentration $\left(N_{c}\right)$ and the liquid 


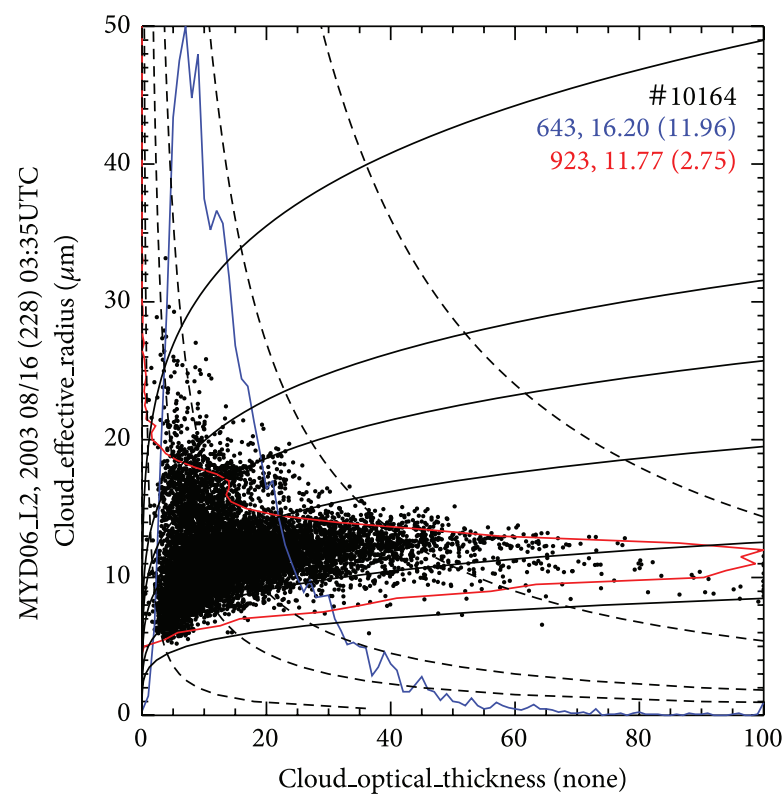

(a) Land, low Cl. (>600 hPa)

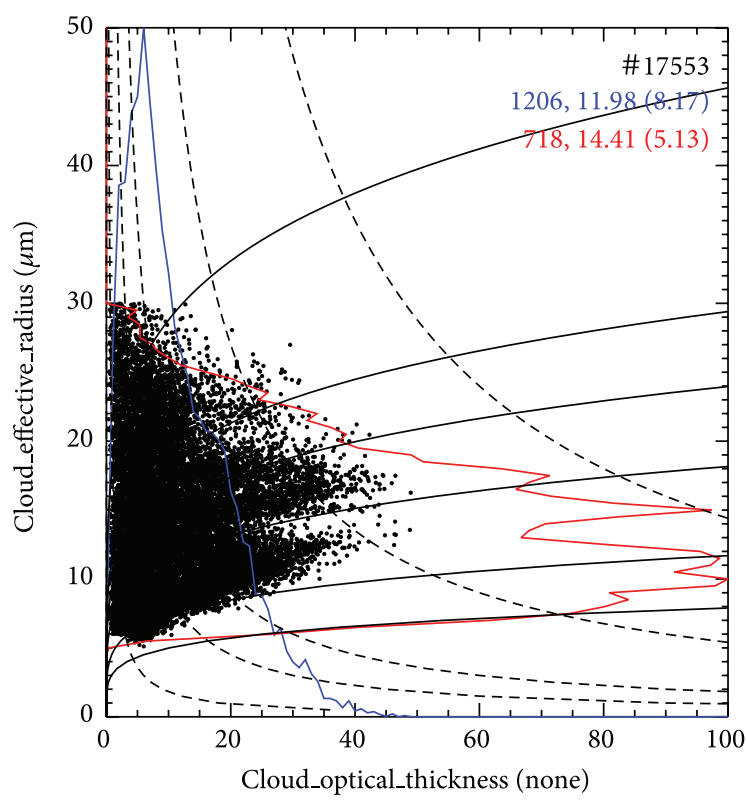

(b) Ocean, low Cl. (>600 hPa)

FIgURE 16: Same as Figure 15 but at 0335 UTC August 16.

water path $(W)$, respectively, following (12) and (13) of [23]. Equation (12) is $\tau_{c}=(8 / 5)(\pi k)^{2}\left(\rho_{w} / \lambda\right) N_{c}^{2} r_{e}(H)^{5}$ and (13) is $\tau_{c}=(9 / 5) \rho_{w}^{-1}\left(W / r_{e}(H)\right)$, where $\rho_{w}$ is the density of liquid water $\left(1.0 \times 10^{6} \mathrm{~g} \mathrm{~m}^{-3}\right), \lambda$ is the adiabatic parameter (set at $2.0 \times 10^{-3} \mathrm{~g} \mathrm{~m}^{-4}$ ), and $H$ is the cloud top height. The air mass factor $k$ in (12) is set to 0.67 over land and 0.80 over the ocean and hence the curved lines of cloud droplet number concentration over land and ocean follow different paths.

At the beginning of the Yamase event shown in Figure 15, the relationships between $\tau$ and $r_{e}$ over land and ocean differed. Over land, the range of $\tau$ values was large (up to 70$)$, while the range of $r_{e}$ was small $(8-15 \mu \mathrm{m})$. As the observed cloud was growing, a weak positive correlation was present between the two factors, as the cloud was created in polluted air (because the $r_{e}$ values were limited to a maximum of $15 \mu \mathrm{m})$. However, over the ocean, although $\tau$ values were as high as 15 , the range of $r_{e}$ values increased to 8$30 \mu \mathrm{m}$. The relationship between $\tau$ and $r_{e}$ over the ocean was slightly negative, and the correlation coefficient was -0.24 ( $P$ value $=0.04$; statistical significance is set at $P<0.05)$. The negative relationship between $\tau$ and $r_{e}$ suggests that drizzle had formed; at the developmental stage of the cloud, $r_{e}$ increased and $\tau$ decreased because the growth of cloud droplets ceased and the liquid water path became stable. The other difference in cloud characteristics between land and ocean was that the liquid water path was up to $50 \mathrm{~g} \mathrm{~m}^{-2}$ over the ocean and up to $300 \mathrm{~g} \mathrm{~m}^{-2}$ over land.

The relationships between $\tau$ and $r_{e}$ over land and ocean are also different during the mature phase of Yamase development (Figure 16). The scatter plot of parameters over the ocean changed significantly from that observed during the early period. The $r_{e}$ range did not change $(5-30 \mu \mathrm{m})$, but $\tau$ increased to 40 , and the cloud liquid water path increased to $300 \mathrm{~g} \mathrm{~m}^{-2}$. A positive relationship was observed between $\tau$ and $r_{e}$, while, at the same time, a negative relationship existed at $\tau$ values of less than 20 . These relationships show that the cloud over the ocean contained a mixture of developing and drizzling phases. This feature is identified in Figures 8 and 9; $r_{e}(\tau)$ values in the south of the analysis area were larger $(>20 \mu \mathrm{m})$ (smaller) than those in the north, and convergence (enhancement of upward motion) occurred in the south of the area (Figure 6).

Over land, large $r_{e}$ values $(>20 \mu \mathrm{m})$ increased still further when $\tau$ was less than 20 , but the positive correlation remained, as did the wide range of $\tau$ values (range of up to 70). Although the relationship between $\tau$ and $r_{e}$ in the Yamase cloud over land indicates a nondrizzling cloud, parts of the cloud developed large droplets, and the ground-based observation data show that some areas experienced small amounts of precipitation (a few $\mathrm{mm} /$ hour) which could not be detected by ground-based radar observation. The discrepancy between satellite and ground-based observations is caused by the difference in the layer (upper or lower) of the observed cloud; the cloud properties retrieved from MODIS are mainly from the upper part of the cloud.

\section{Conclusions}

Although the formation process is not fully understood, it is known that the Yamase cloud forms over the ocean and then extends to cover coastal areas and land under the influence of an easterly or northeasterly wind associated with the Okhotsk High. The present study investigated the landocean contrast in Yamase cloud properties, such as cloud top pressure, $r_{e}, \tau$, and cloud water paths, during the summer of 2003, using satellite observational data. The summer of 2003 
(July-August) was selected as the analysis period for the study because it was the coolest Yamase summer during a decade of observations and because there were many observational cases of Yamase clouds during this time.

In conclusion, the characteristics of the Yamase cloud are generally similar to those of stratus clouds, but, in the Yamase cloud, the effective radius over land is smaller and the optical thickness over land is greater than that typical for stratus clouds. We suggest that the main factors influencing the land-ocean contrast in Yamase cloud properties are aerosol characteristics and vertical stability. In particular, we showed that the precipitous mountain facing the Pacific Ocean (on the windward side) and the region of complex topography enforce an updraft of moist air, resulting in an unstable environment and an inhomogeneous distribution of Yamase cloud over land. Further discussions about lowlevel cloud formation and land-ocean differences require the simultaneous detection of the types and amounts of aerosols that form CCN. However, at the present time, it is difficult to simultaneously obtain cloud and aerosol properties on a synoptic scale based on presently available observational data.

Even in current numerical mesoscale models, the simulation of the Yamase cloud is not sufficiently accurate; thus the model requires more realistic parameterization of stratus clouds [34], interaction mechanisms between cloud formation processes in the meteorological field at subgrid scales and synoptic scales [35], and air-sea interaction processes through lower cloud formation [20]. A more detailed knowledge of the properties of the Yamase cloud over land is required to enable us to consider the impact of the Yamase cloud on weather conditions as well as to develop a better understanding of variations in the characteristics of the cloud over land. We believe that the results of the present study will lead to improvements in the numerical models and especially cloud microphysics parameterization associated with mesoscale or smaller scale dynamical effects.

\section{Conflict of Interests}

The authors declare that there is no conflict of interests regarding the publication of this paper.

\section{Acknowledgments}

The authors would like to thank Dr. Kazuaki Kawamoto of Nagasaki University, Dr. Yasu-Masa Kodama of Hirosaki University, and Dr. Takashi Nakajima of Tokai University for their valuable comments and suggestions. The authors also thank the MODIS cloud and aerosol product teams for providing the cloud and aerosol parameter data and the JMA for providing meteorological data. The cloud and aerosol parameters used in the present study were obtained from MODIS cloud and aerosol products (MOD06, MYD06/MOD04, and MYD04). The meteorological data used in the present study were from the mesoscale numerical model and the AMeDAS operated by the JMA. The authors would like to thank the reviewers for their useful comments and suggestions.
The present study was partially supported by a Grant-inAid for Scientific Research on Innovative Areas 22106004 from the Ministry of Education, Culture, Sports, Science and Technology (MEXT), Japan, and under the Research Program on Climate Change Adaptation (RECCA).

\section{References}

[1] K. Ninomiya and H. Mizuno, "Anomaly cold spell in summer over North eastern Japan caused by northeasterly wind from polar maritime airmass - part 2: structure of the northeasterly flow from polar maritime airmass," Journal of the Meteorological Society of Japan, vol. 63, pp. 859-871, 1985.

[2] J. R. Norris, Y. Zhang, and J. M. Wallace, "Role of low clouds in summertime atmosphere-ocean interactions over the North Pacific," Journal of Climate, vol. 11, no. 10, pp. 2482-2490, 1998.

[3] S. Asano, "A study on the cloud formation and modification processes and numerical modeling of YAMASE clouds, the research report for Grant-in-Aid for Scientific Research (A)," 2008, Grant Number 17204039.

[4] M. Kojima, S. Asano, and H. Iwabuchi, "Time-variations of optical and Micro-physical properties of yamase clouds estimated from shipboard experiments and satellite remote sensing in June 2003," Sola, vol. 2, pp. 45-48, 2006.

[5] T. Y. Nakajima and T. Nakajima, "Wide-area determination of cloud microphysical properties from NOAA AVHRR measurements for FIRE and ASTEX regions," Journal of the Atmospheric Sciences, vol. 52, no. 23, pp. 4043-4059, 1995.

[6] Q. H. Qingyuan Han, W. B. Rossow, and A. A. Lacis, "Nearglobal survey of effective droplet radii in liquid water clouds using ISCCP data," Journal of Climate, vol. 7, no. 4, pp. 465-497, 1994.

[7] K. Kawamoto and T. Nakajima, "A global determination of cloud microphysics with AVHRR remote sensing," Journal of Climate, vol. 14, no. 9, pp. 2054-2068, 2001.

[8] T. Yuan, Z. Li, R. Zhang, and J. Fan, "Increase of cloud droplet size with aerosol optical depth: an observation and modeling study," Journal of Geophysical Research, vol. 113, no. D4, 2008.

[9] M. D. King, S. C. Tsay, S. Platnick, M. Wang, and K. N. Liou, Cloud Retrieval Algorithms for MODIS: Optical Thickness, Effective Particle Radius, and Thermodynamic Phase, 1998.

[10] W. P. Menzel, R. A. Frey, and B. A. Baum, Cloud Top Properties and Cloud Phase 5-Algorithm Theoretical Basis Document, 2010.

[11] R. E. Holz, S. A. Ackerman, F. W. Nagle et al., "Global Moderate Resolution Imaging Spectroradiometer (MODIS) cloud detection and height evaluation using CALIOP," Journal of Geophysical Research D, vol. 114, no. 8, Article ID D00A19, 2009.

[12] M. J. Garay, S. P. de Szoeke, and C. M. Moroney, "Comparison of marine stratocu-mulus cloud top heights in the Southeastern Pacific retrieved from satellites with coincident ship-based observations," Journal of Geophysical Research, vol. 113, Article ID D18204, 2008.

[13] H. Harshvardhan, G. Zhao, L. Di Girolamo, and R. N. Green, "Satellite-observed location of stratocumulus cloud-top heights in the presence of strong inversions," IEEE Transactions on Geoscience and Remote Sensing, vol. 47, no. 5, pp. 1421-1428, 2009.

[14] E. M. Wilcox, H. Harshvardhan, and S. Platnick, "Estimate of the impact of absorbing aerosol over cloud on the MODIS retrievals of cloud optical thickness and effective radius using 
two independent retrievals of liquid water path," Journal of Geophysical Research D, vol. 114, no. 5, Article ID D05210, 2009.

[15] K. Takano, "Observations and forecasts for the summer in Japan in 2003," Tenki, vol. 52, pp. 581-585, 2005 (Japanese).

[16] K. Saito, T. Fujita, Y. Yamada et al., "The operational JMA nonhydrostatic mesoscale model," Monthly Weather Review, vol. 134, pp. 1266-1298, 2006.

[17] Y. Makihara, "Algorithms for precipitation nowcasting focused on detailed analysis using radar and raingauge dat," Tech. Rep., Meteorological Research Institute, 2000, http://www.mrijma.go.jp/Publish/Technical/DATA/VOL_39/39_063.pdf.

[18] "Daily Weather Charts of July 2003," Tenki (Monthly Journal of Meteolorogical Society of Japan), vol. 50, no. 9, pp. 730-734, 2003.

[19] "Daily Weather Charts of August 2003," Tenki (Monthly Journal of Meteolorogical Society of Japan), vol. 50, no. 10, pp. 808-812, 2003.

[20] S. Koseki, T. Nakamura, H. Mitsudera, and Y. Wang, "Modeling low-level clouds over the Okhotsk Sea in summer: cloud formation and its effects on the Okhotsk high," Journal of Geophysical Research D, vol. 117, no. 5, Article ID D05208, 2012.

[21] H. Nakamura and T. Fukamachi, "Evolution and dynamics of summertime blocking over the Far East and the associated surface Okhotsk high," Quarterly Journal of the Royal Meteorological Society, vol. 130, no. 599, pp. 1213-1233, 2004.

[22] H. Takai and H. Kawamura, "Cloud appearance rate in the Yamase days derived from the NOAA satellite and AMeDAS observations," Tenki, vol. 49, no. 12, pp. 17-24, 2002 (Japanese).

[23] K. Suzuki, T. Nakajima, T. Y. Nakajima, and A. P. Khain, "A study of microphysical mechanisms for correlation patterns between droplet radius and optical thickness of warm clouds with a spectral bin microphysics cloud model," Journal of the Atmospheric Sciences, vol. 67, no. 4, pp. 1126-1141, 2010.

[24] L. A. Remer, D. Tanré, Y. J. Kaufman, R. Levy, and S. Mattoo, "Algorithm for remote sensing of tropospheric aerosol from MODIS: collection 5," Product ID: MOD04/MYD04, 2006, http://modis-atmos.gsfc.nasa.gov/MOD04 L2/atbd.html.

[25] R. C. Levy, L. A. Remer, D. Tanré, S. Mattoo, and Y. J. Kaufman, "Algorithm for remotesensing of tropospheric aerosol over dark targets from MODIS: Collections 005 and 051: revision 2," 2009, http://modis-atmos.gsfc.nasa.gov/MOD04 L2/atbd.html.

[26] R. C. Levy, L. A. Remer, R. G. Kleidman et al., "Global evaluation of the Collection 5 MODIS dark-target aerosol products over land," Atmospheric Chemistry and Physics, vol. 10, no. 21, pp. 10399-10420, 2010.

[27] T. Takemura, H. Okamoto, Y. Maruyama, A. Numaguti, A. Higurashi, and T. Nakajima, "Global three-dimensional simulation of aerosol optical thickness distribution of various origins," Journal of Geophysical Research D, vol. 105, no. 14, pp. 1785317873, 2000.

[28] T. Takemura, T. Nakajima, O. Dubovik, B. N. Holben, and S. Kinne, "Single-scattering albedo and radiative forcing of various aerosol species with a global three-dimensional model," Journal of Climate, vol. 15, no. 4, pp. 333-352, 2002.

[29] P. Squires, "The microstructure and colloidal stability of warm clouds-part II: The Causes of the Variations in Microstructure," Tellus, vol. 10, no. 2, pp. 262-271, 1958.

[30] S. Twomey and P. Squires, "The influence of cloud nucleus population on the microstructure and stability of convective clouds," Tellus, vol. 11, no. 4, pp. 408-411, 1959.

[31] P. Squires, "The microstructure and colloidal stability of warm clouds-part I: The Relation between Structure and Stability," Tellus, vol. 10, no. 2, pp. 256-261, 1958.
[32] T. Nakajima and M. D. King, "Determination of the optical thickness and effective particle radius of clouds from reflected solar radiation measurements-part I: theory," Journal of the Atmospheric Sciences, vol. 47, no. 15, pp. 1878-1893, 1990.

[33] T. Nakajima, M. D. King, L. F. Radke, and J. D. Spinhirne, "Determination of the optical thickness and effective particle radius of clouds from reflected solar radiation measurementspart II: marine stratocumulus observations," Journal of the Atmospheric Sciences, vol. 48, no. 5, pp. 728-750, 1991.

[34] R. Nagasawa, T. Iwasaki, S. Asano, K. Saito, and H. Okamoto, "Resolution dependence of nonhydrostatic models in simulating the formation and evolution of low-level clouds during a "Yamase" event," Journal of the Meteorological Society of Japan, vol. 84, no. 6, pp. 969-987, 2006.

[35] N. Ishizaki, I. Takayabu, M. Oh'izumi et al., "Improved performance of simulated Japanese climate with a Multi-Model ensemble," Journal of the Meteorological Society of Japan, vol. 90, pp. 235-254, 2012. 

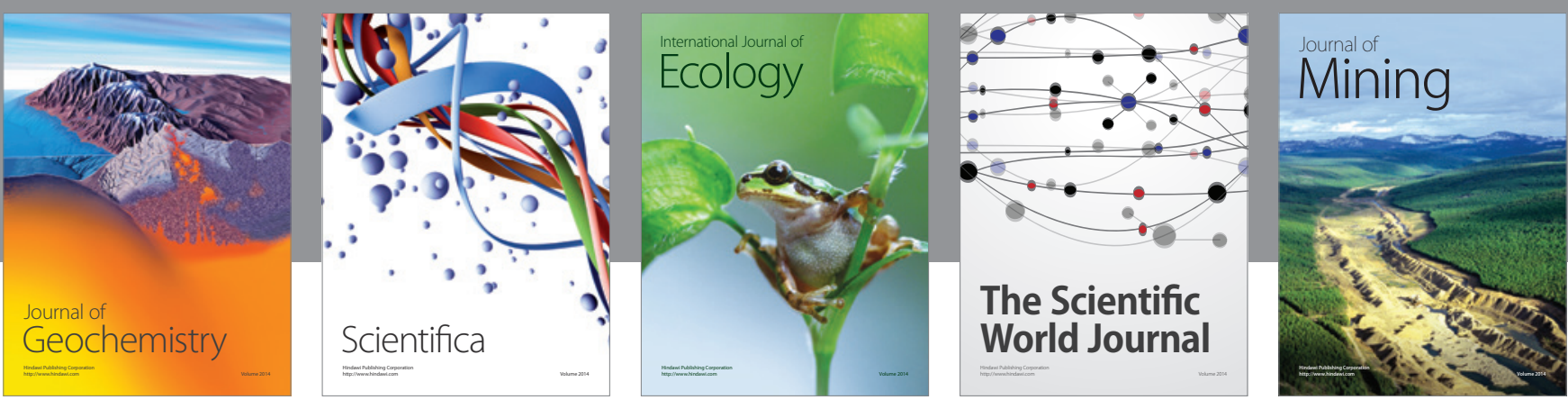

The Scientific World Journal
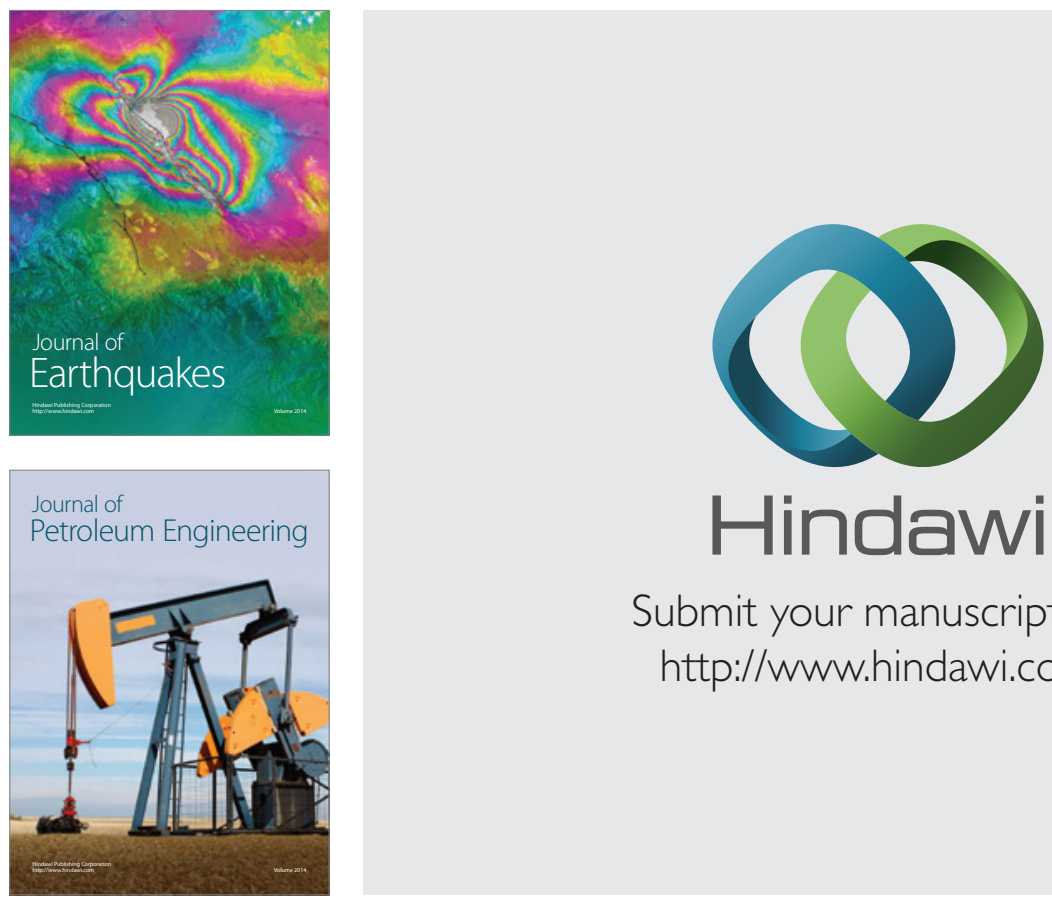

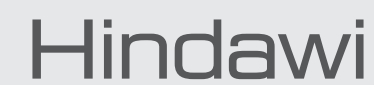

Submit your manuscripts at

http://www.hindawi.com
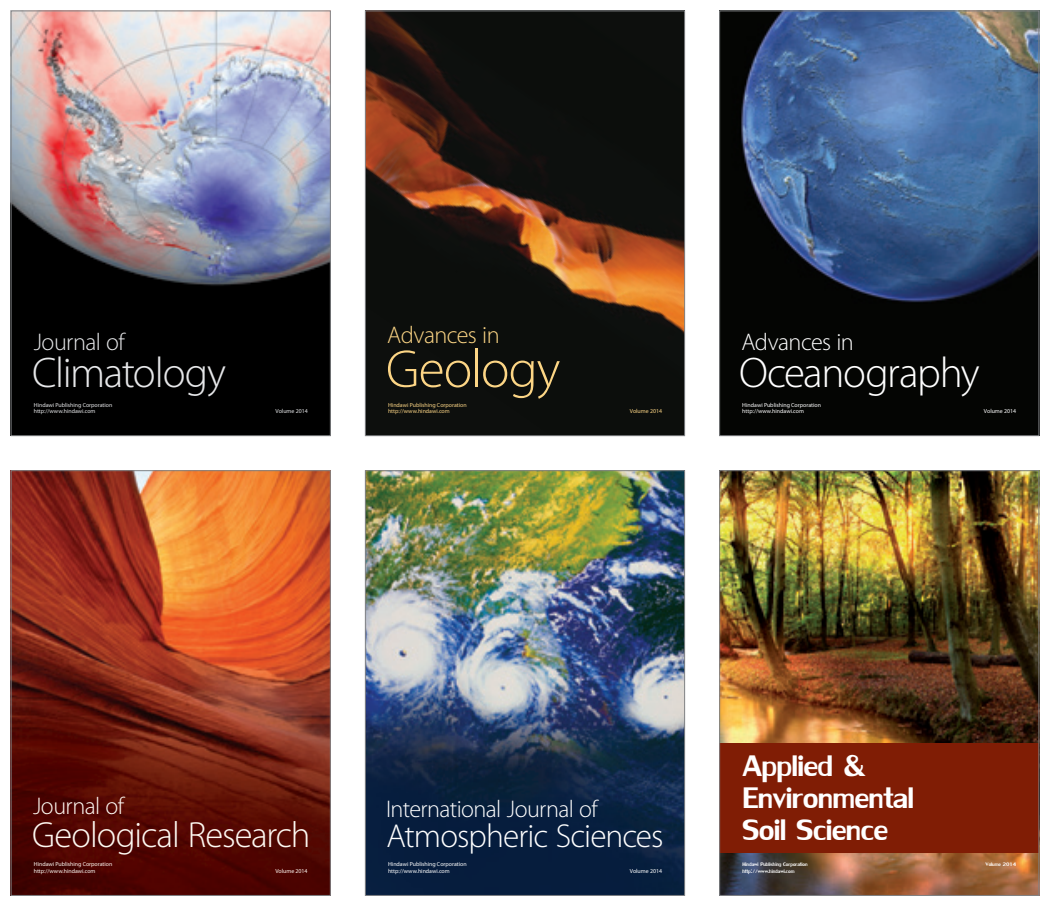
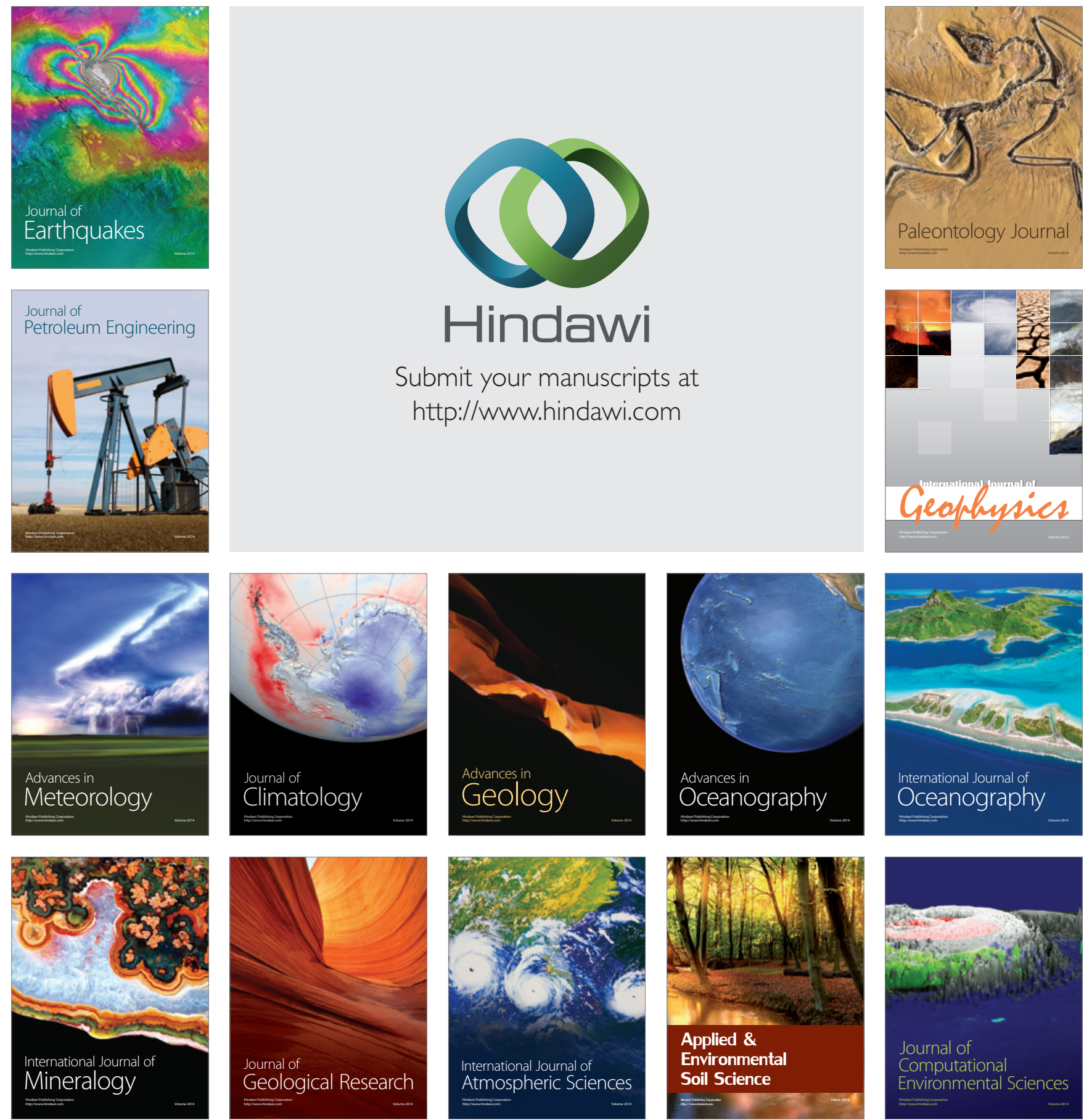